\title{
Putty-Clay and Investment: A Business Cycle Analysis ${ }^{1}$
}

\author{
Simon Gilchrist \\ Boston University and NBER \\ 270 Bay State Road \\ Boston, MA 02215 \\ sgilchri@bu.edu \\ and \\ John C. Williams \\ Board of Governors of the Federal Reserve System \\ Mail Stop 67 \\ Washington, DC 20551 \\ jwilliams@frb.gov
}

June, 1998

\begin{abstract}
This paper develops a dynamic stochastic general equilibrium model with putty-clay technology that incorporates embodied technology, investment irreversibility, and variable capacity utilization. Low short-run capital-labor substitutability native to the putty-clay framework induces the putty-clay effect of a tight link between changes in capacity and movements in employment and output. As a result, persistent shocks to technology or factor prices generate business cycle dynamics absent in standard neoclassical models, including a prolonged hump-shaped response of hours, persistence in output growth, and positive comovement in the forecastable components of output and hours. Capacity constraints result in a nonlinear aggregate production function that implies asymmetric responses to large shocks with recessions steeper and deeper than expansions. Minimum distance estimation of a two-sector model that nests putty-clay and neoclassical production technologies supports a significant role for putty-clay capital in explaining business-cycle and medium-run dynamics.
\end{abstract}

Keywords: putty-clay, vintage capital, business cycle, irreversibility, capacity utilization.

JEL Classification: D24, E22, E32

\footnotetext{
${ }^{1}$ We are indebted to Steven Sumner for exemplary research assistance. We wish to thank Flint Brayton, Jeff Cambell, Thomas Cooley, Russel Cooper, Sam Kortum, John Leahy, Scott Schuh, Dan Sichel, and participants at presentations at the NBER Impulse and Propagation Workshop and Economic Fluctuations Meeting, Columbia University, Harvard University, NYU, the University of Maryland, the Federal Reserve Bank of New York, and the Board of Governors of the Federal Reserve for helpful comments. The opinions expressed here are not necessarily shared by the Board of Governors of the Federal Reserve System or its staff
} 


\section{Introduction}

In this paper we develop a dynamic stochastic general equilibrium model based on the putty-clay technology introduced by Johansen (1959). The putty-clay model possesses a number of attractive features typically absent from models based on neoclassical production functions, including a nonlinear short-run aggregate production function, irreversible investment, variable capacity utilization, and endogenous machine replacement. We investigate the implications of putty-clay technology for macroeconomic dynamics at business cycle and medium-run frequencies. ${ }^{2} \mathrm{~A}$ key finding in the paper is that low short-run capital-labor substitutability native to the putty-clay framework induces the putty-clay effect of a tight link between changes in capacity and movements in employment and output. In the short-run, an expansion of employment quickly confronts sharp increases in marginal costs, owing to capacity constraints. Once new capacity is in place, a sustained boom in employment and output ensues, as firms fully employ new machines without reducing utilization rates on existing capacity.

The putty-clay technology described above has two major implications for business-cycle dynamics. First, persistent shocks to technology or factor prices generate a prolonged hump-shaped response of hours, persistence in output growth, and positive comovement between the forecastable components of output and hours. These features of the business cycle, documented by Cogley and Nason (1995) and Rotemberg and Woodford (1996), are absent in standard neoclassical models where the response of hours peaks upon the impact of the shock and the dynamic response of output closely follows that of the shock. ${ }^{3}$ Second, large shocks generate asymmetric responses of output and hours, with recessions steeper and deeper than expansions. This asymmetric response is consistent with the empirical evidence documented by Neftci (1984) and others, and reflects the fact that the short-run elasticity of output with respect to labor is decreasing in the quantity of labor employed.

The empirical relevance of putty-clay technology is confirmed by minimum distance estimation of a two-sector model that formally nests both the putty-clay and neoclassical model within a common econometric framework. We find that the dis-

\footnotetext{
${ }^{2}$ In a recent paper, Caballero and Hammour (1998) study medium-run issues using a putty-clay model. See also Malinvaud (1980) and Blanchard (1997).

${ }^{3}$ Classic examples of neoclassical models are found in the real business cycle literature of Kydland and Prescott (1982) and Hansen (1985).
} 
tance between model and data moments is minimized for an estimated putty-clay share of total output that is on the order of $50-75 \%$. The data overwhelmingly reject the restriction of no role for putty-clay capital.

The putty-clay model provides an intrinsically appealing description of capital accumulation. In this framework, capital goods embody the level of technology and the choice of capital intensity made at the time of their creation. Ex ante, the choice of capital intensity - the amount of capital to be used in conjunction with one unit of labor - is based on a standard neoclassical production function. Ex post, the production function is of the Leontief form with a zero-one utilization decision based on the output per hour of a given piece of capital relative to the prevailing wage rate. Over time, as the economy grows and real wages rise, older vintages of capital become too costly to operate given their current labor requirements and they are mothballed or scrapped. ${ }^{4}$

Putty-clay models have a long history in both the growth (Johansen (1959), Solow (1962), Phelps (1963), Cass and Stiglitz (1969), Sheshinski (1967) and Calvo (1976)) and investment literatures (Bischoff (1971), Ando, Modigliani, Rasche and Turnovsky (1974)). Due in part to computational complexities, these past literatures mainly limited themselves to characterizing the long-run features of a puttyclay economy or to partial equilibrium analysis of the investment sector. More recently, interest in real business cycle models has spurred a revival in alternative specifications of technology, including putty-clay. ${ }^{5}$ Atkeson and Kehoe (1994) develop a model where the energy-intensity of production is the putty-clay factor. Their model possesses the property of a cutoff rule for utilizing capital — based on the price of energy as opposed to the wage - but their dynamic analysis focuses on the case where capital is always fully utilized. Cooley, Hansen and Prescott (1995) study a model where each period physical capital is assigned to plots of land, the supply of which is assumed to be fixed for the dynamic analysis. Although this model features variable capacity utilization, the assumption that the land intensity of capital can be freely changed after one period effectively cuts the dynamic link

\footnotetext{
${ }^{4}$ The effects of technological lock-in motivate the machine replacement problem first addressed by Johansen (1959) and Calvo (1976), and more recently formalized in a dynamic programming environment by Cooper and Haltiwanger (1993) and Cooley, Greenwood and Yorukoglu (1994).

${ }^{5}$ Vintage models have also experienced a resurgence of late as witnessed by Benhabib and Rustichini (1991), Benhabib and Rustichini (1993), Caballero and Hammour (1996), Campbell (1994), Cooper, Haltiwanger and Power (1995), Boucekkine, Germain and Licandro (1997), and Greenwood, Hercowitz and Krusell (1997).
} 
between capital and labor that is key to the putty-clay effect.

Our model incorporates what we view as the essential features of the puttyclay framework, including variable capacity utilization and investment irreversibility. Although the assumption of ex post Leontief technology may at first seem unrealistically stark, the resulting aggregate production function embeds, depending on the model's parameterization, both the relatively flat short-run supply curve usually associated with a neoclassical model and a reverse L-shaped supply curve traditionally associated with the putty-clay framework. In addition, the model's micro-foundations are largely consistent with microeconomic evidence on the importance of plant shutdowns as a short-run adjustment margin (Bresnahan and Ramey (1994)) and the lumpiness of investment at the plant level (Doms and Dunne (1993), Cooper et al. (1995), Caballero, Engel and Haltiwanger (1995)).

The distinguishing features of the model developed in this paper are nicely illustrated by the experiment of a reduction in the cost of producing new capital goods. This reduction in capital cost raises the return to new capital and causes a surge in investment, which over time leads to rising aggregate output and consumption. Initially, however, firms' efforts to raise employment encounter capacity constraints owing to the putty-clay nature of capital. As a result of this low short-run substitutibility of labor for capital, the initial aggregate response of both output and hours is muted. To efficiently increase production, firms invest in new capacity, that, once in place, can be utilized by an expanded workforce. Ex post fixity of the capital-labor ratio for existing capacity implies that labor can only be reallocated to new machines at the cost of mothballing existing capacity. Therefore, there is an incentive to simultaneously utilize both new and exisiting capital. This dynamic linkage between capital and labor causes hours and output to rise together for a sustained period of time following the initial burst of investment, generating the putty-clay effect.

The dynamic response to a large increase in the cost of new capital goods differs in some respects from that described above. In this case, a large fraction of the overall adjustment of output and hours is accomplished through an immediate reduction in capacity utilization. Thus, the putty-clay model naturally delivers asymmetric responses to positive and negative shocks, with the asymmetries increasing in the magnitude of the shock. 


\section{The Model}

In this section we describe the model and derive the equilibrium conditions. Each capital good possesses two defining qualities: its level of embodied technology and its capital intensity. The underlying or ex ante production technology is assumed to be Cobb-Douglas with constant returns to scale, but for capital goods in place, production possibilities take the Leontief form: there is no ex post substitutability of capital and labor. In addition to aggregate technological change, we allow for the existence of idiosyncratic uncertainty regarding the productivity of investment projects. As in Campbell (1994), the introduction of heterogeneity within vintages smooths the aggregate allocation and simplifies computation of the equilibrium. More importantly, such idiosyncratic uncertainty implies the existence of a well-defined aggregate production function despite the Leontief nature of the microeconomic utilization choice.

Once in place, capital goods are irreversible, that is, they cannot be converted into consumption goods or capital goods with different embodied characteristics, and have zero scrap value. Firms can choose, however, whether or not to operate a given unit of capital depending on the profitability of doing so in the current economic environment. We assume that there are no costs of taking machines or workers on- and off-line. As such, the utilization choice is purely atemporal. The optimal utilization choice for each unit of capital is determined by the difference between the (labor) productivity of the capital and the cost of utilizing the capital, which in the absence of other costs equals the wage rate. If the productivity of a unit of capital exceeds the wage rate, the capital is used in production, otherwise, it is not. In equilibrium, the wage rate, capacity utilization rate, and levels of employment, production, consumption, and investment are determined jointly by the dynamic optimizing behavior of households and firms. To characterize the equilibrium allocation, we first discuss the optimization problem at the project level and then describe aggregation from the project level to the aggregate allocation.

\subsection{The Investment Decision}

Each period a set of new investment "projects" becomes available. Constant returns to scale implies an indeterminacy of scale at the level of projects, so without loss of generality, we normalize all projects to employ one unit of labor at full capacity. We 
refer to these projects as "machines." Capital goods require one period for initial installation and then are productive for $M \geq 1$ periods. The productive efficiency of machine $i$ initiated at time $t$ is affected by two stochastic productivity terms, one idiosyncratic, one aggregate. In addition, we assume all machines, regardless of their relative efficiency, fail at an exogenously given rate that varies by the age of the machine. In summary, capital goods are heterogeneous and are characterized by three attributes: vintage (age and level of aggregate embodied technology), capitalintensity, and the realized value of the idiosyncratic productivity term.

The productivity of each machine, initiated at time $t$, differs according to the log-normally distributed random variable, $\theta_{i, t}$, where

$$
\log \theta_{i, t} \sim N\left(\log \theta_{t}-\frac{1}{2} \sigma^{2}, \sigma^{2}\right) .
$$

The aggregate index $\theta_{t}$ measures the mean level of embodied technology of vintage $t$ capital goods and $\sigma^{2}$ is the variance of the idiosyncratic shock. The mean correction term $-\frac{1}{2} \sigma^{2}$ implies $E\left(\theta_{i, t} \mid \theta_{t}\right)=\theta_{t}$. We assume $\theta_{t}$ follows a stochastic process with mean gross growth rate $(1+g)^{1-\alpha}$. For the sake of notational clarity, in the following discussion we abstract from disembodied aggregate technological change of the type typical in the real business cycle literature. The inclusion of a stochastic disembodied technology process is straightforward and used in section 3 when analyzing model dynamics.

Before investment decisions are made, the economy-wide level of vintage technology $\theta_{t}$ is observed but the idiosyncratic shock to individual machines is not. We also assume that after the revelation of the idiosyncratic shock, further investments in existing machines are not possible. Subject to the constraint that labor employed, $L_{i, t+j}$, is nonnegative and less than or equal to unity (capacity), final goods output produced in period $t+j$ by machine $i$ of vintage $t$ is

$$
Y_{i, t+j}=\theta_{i, t} k_{i, t}^{\alpha} L_{i, t+j},
$$

where $k_{i, t}$ is the capital-labor ratio chosen at the time of installation. Denote the labor productivity of a machine by

$$
X_{i, t} \equiv \theta_{i, t} k_{i, t}^{\alpha} .
$$

The only variable cost to operating a machine is the wage rate, $W_{t}$. Idle machines incur no variable costs and have the same capital costs as operating machines. ${ }^{6}$

\footnotetext{
${ }^{6}$ The model can be extended to allow for a fixed labor cost per unit of capital. Under such a
} 
Figure 1: Steady-state Distribution of Labor Productivity

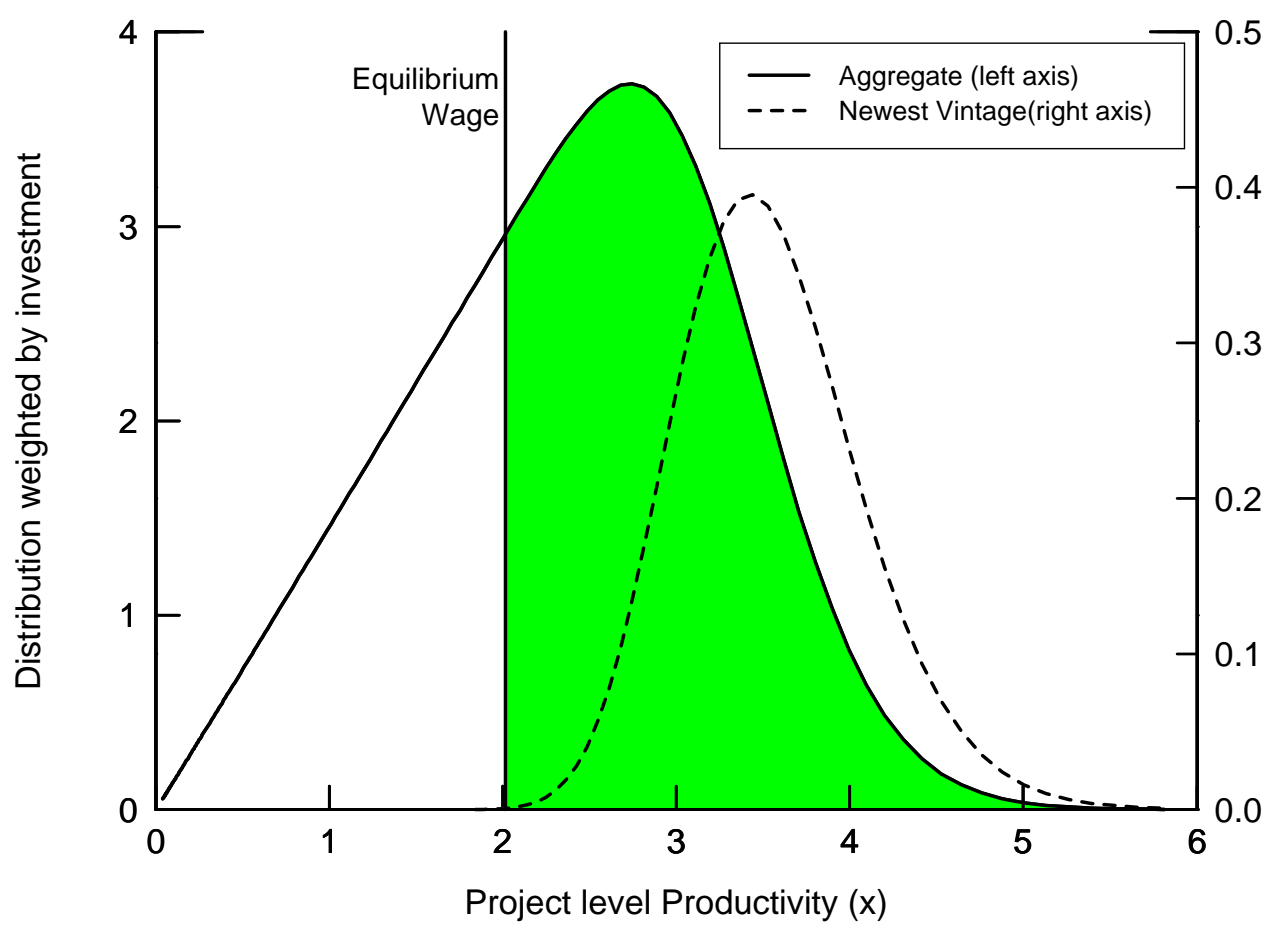

Given the Leontief structure of production, these assumptions imply a cutoff value for the minimum efficiency level of machines used in production: those with productivity $X_{i, t} \geq W_{t}$ are run at capacity, while those less productive are left idle.

To illustrate these ideas, Figure 1 shows the steady-state distribution of labor productivity for the model calibrated to parameters specified below. The height of the distribution reflects the number of machines at any given productivity level. The cutoff value for the wage is shown as a vertical line. Capital goods with productivity lying to the right of the cutoff are used in production, those to the left are idle. Capital utilization is given by the area in the shaded region divided by the total area under the distribution.

Figure 1 also shows the distribution of labor productivity for the most recent vintage (right scale). Its position on the horizonal axis reflects both the current level of technology and the capital intensity of new machines. Owing to trend growth specification, it is optimal to permanently scrap machines whose efficiency falls below some cutoff. This modification substantially complicates the investment decision and is left for future research. 
and relatively long-lived capital, the average labor productivity of the most recent vintage is substantially higher than the average labor productivity of existing machines. Obsolescence through embodied technical change implies that old vintages have lower average utilization rates than new vintages. Note that trend growth in investment - due to population growth and technological change - causes the aggregate distribution to be skewed.

To derive the equilibrium allocation of labor, capital intensity, and investment, we begin by analyzing the investment and utilization decision for a single machine. Define the time $t$ discount rate for time $t+j$ income by $\tilde{R}_{t, t+j} \equiv \prod_{s=1}^{j} R_{t+s}^{-1}$, where $R_{t+s}$ is the one period gross interest rate at time $t+s$. At the machine level, capital intensity is chosen to maximize the present discounted value of profits to the machine:

$$
\begin{aligned}
\max _{k_{i, t},\left\{L_{i, t+j}\right\}_{j=1}^{M}} E_{t}\left\{-k_{i, t}+\sum_{j=1}^{M} \tilde{R}_{t, t+j}\left(1-\delta_{j}\right)\left(X_{i, t}-W_{t+j}\right) L_{i, t+j}\right\}, \\
\text { s.t. } \quad 0 \leq L_{i, t+j} \leq 1, \quad j=1, \ldots, M, \\
\quad 0<k_{i, t}<\infty,
\end{aligned}
$$

where $\delta_{j}$ is the probability a machine has exogenously failed by $\mathrm{j}$ periods and expectations are taken over labor productivity, whose realization depends on the time $t$ idiosyncratic shock, and future values of wages and interest rates.

Because investment projects are identical ex ante, the optimal choice of the capital-labor ratio is equal across all machines in a vintage; that is, $k_{i, t}=k_{t}, \forall i$. Denote the average productivity of the entire stock of vintage $t$ capital by $X_{t}=$ $\theta_{t} k_{t}^{\alpha}$. Capital utilization for vintage $s$ at time $t$ is the ratio of labor employed to employment capacity of the vintage, given by $\operatorname{Pr}\left(X_{i, s}>W_{t} \mid W_{t}, \theta_{t}\right)$. Given the log-normal distribution for $\theta_{i, t}$ we obtain:

$$
\operatorname{Pr}\left(X_{i, s}>W_{t} \mid W_{t}, \theta_{t}\right)=1-\Phi\left(z_{t}^{s}\right)
$$

where $\Phi(\cdot)$ is the c.d.f. of the standard normal and

$$
z_{t}^{s} \equiv \frac{1}{\sigma}\left(\log W_{t}-\log X_{s}+\frac{1}{2} \sigma^{2}\right)
$$

Similarly, capacity utilization for vintage $s$ at time $t$ is the ratio of actual output produced from the capital of a given vintage to the level of output that could be 
produced at full capital utilization. Letting $F(\cdot)$ denote the cdf of $X_{i, t}$, capacity utilization is formally defined as

$$
\frac{\int_{X_{i s}>W_{t}}^{\infty} X_{i, s} d F\left(X_{i, s}\right)}{\int_{0}^{\infty} X_{i, s} d F\left(X_{i, s}\right)}=\left(1-\Phi\left(z_{t}^{s}-\sigma\right)\right)
$$

where the equality follows from the log-normality of $X_{i, t}{ }^{7}$

If all machines were fully utilized, labor productivity would simply equal $X_{t}$. With partial utilization, labor productivity also depends on capital and capacity utilization. The average product of labor for vintage $s$ capital at time $t$, is

$$
A P L_{t}^{s}=\frac{1-\Phi\left(z_{t}^{s}-\sigma\right)}{1-\Phi\left(z_{t}^{s}\right)} X_{s}
$$

Letting $\phi(\cdot)$ denote the p.d.f. of the standard normal, the marginal product of labor for vintage $s$ capital at time $t$ is

$$
M P L_{t}^{s}=\frac{\phi\left(z_{t}^{s}-\sigma\right)}{\phi\left(z_{t}^{s}\right)} X_{s}
$$

For any given vintage, the marginal product of labor is equal to the efficiency of the least productive machine of the vintage in operation. ${ }^{8}$

Expected net income in period $t$ from a vintage $s$ machine, $\pi_{t}^{s}$, conditional on $W_{t}$, is given by

$$
\pi_{t}^{s}=\left(1-\delta_{t-s}\right)\left(\left(1-\Phi\left(z_{t}^{s}-\sigma\right)\right) X_{s}-\left(1-\Phi\left(z_{t}^{s}\right)\right) W_{t}\right)
$$

Substituting this expression for net income into equation 1 eliminates the future choices of labor from the investment problem. The remaining choice variable is $k_{t}$. The first order condition for an interior solution for $k_{t}$ is given by ${ }^{9}$

$$
k_{t}=\alpha E_{t}\left\{\sum_{j=1}^{M} \tilde{R}_{t, t+j}\left(1-\delta_{j}\right)\left(1-\Phi\left(z_{t+j}^{t}-\sigma\right)\right) X_{t}\right\} .
$$

\footnotetext{
${ }^{7}$ Capacity utilization may be expressed as $\left[E\left(X_{i, s} \mid X_{i, s}>W_{t}\right) / E\left(X_{i, t}\right)\right] \operatorname{Pr}\left(X_{i, s}>W_{t}\right)$. We then use the formula for the expectation of a truncated $\log$-normal: If $\log (\mu) \sim N\left(\zeta, \sigma^{2}\right)$, then $E(\mu \mid \mu>\chi)=\frac{(1-\Phi(\gamma-\sigma))}{(1-\Phi(\gamma))} E(\mu)$ where $\gamma=(\log (\chi)-\zeta) / \sigma$ (Johnson, Kotz and Balakrishnan 1994).

${ }^{8}$ Normalizing the quantity of machines at unity, marginal product equals the increment to machine output obtained by reducing the efficiency cutoff $W_{t}$, divided by the increment to labor input obtained by reducing the cutoff $W_{t}$. The increment to output equals $\frac{\partial\left(1-\Phi\left(z_{t}^{s}-\sigma\right) X_{s}\right)}{\partial z_{t}^{s}} \frac{\partial z_{t}^{s}}{\partial W_{t}}$, while the increment to labor equals $\frac{\partial\left(1-\Phi\left(z_{t}^{s}\right)\right)}{\partial z_{t}^{s}} \frac{\partial z_{t}^{s}}{\partial W_{t}}$.

${ }^{9}$ This first order condition is obtained by taking the derivative of the profit function with respect to $k_{t}$, recognizing that in equilibrium, the marginal machine earns zero quasi-rents so that $\frac{\partial \pi_{t}^{s}}{\partial z_{t}^{s}} \equiv$ $\frac{1}{\sigma} \phi\left(z_{t}^{s}-\sigma\right) X_{s}-\frac{1}{\sigma} \phi\left(z_{t}^{s}\right) W_{t}=0$.
} 
New machines are put into place until the value of a new machine (the present discounted value of net income) is equal to the cost of a machine $\left(k_{t}\right)$

$$
\begin{aligned}
k_{t}= & E_{t}\left\{\sum_{j=1}^{M} \tilde{R}_{t, t+j}\left(1-\delta_{j}\right)\left(1-\Phi\left(z_{t+j}^{t}-\sigma\right)\right) X_{t}\right. \\
& \left.-\sum_{j=1}^{M} \tilde{R}_{t, t+j}\left(1-\delta_{j}\right)\left(1-\Phi\left(z_{t+j}^{t}\right)\right) W_{t+j}\right\}
\end{aligned}
$$

This is the free-entry or zero-profit condition. The first term on the right hand side of equation 3 reflects the expected present discounted value of output adjusted for the probability that the machine's idiosyncratic productivity draw is too low to profitably operate the machine in period $t+j$. The second term likewise reflects the expected present value of the wage bill, adjusted for the probability of such a shutdown. This condition must hold as long as there is gross investment in period $t .{ }^{10}$ Equations 2 and 3 jointly imply that, in equilibrium, the expected present value of the wage bill equals $(1-\alpha)$ times the expected present value of revenues.

\section{$2.2 \quad$ Aggregation}

Aggregation of machine-level labor inputs and output is a two-step process. First, labor input and output of machines in each vintage are aggregated into vintage totals. Second, inputs and outputs from the M productive vintages are summed to yield aggregate values. Total labor employment, $L_{t}$, is

$$
L_{t}=\sum_{j=1}^{M}\left(1-\Phi\left(z_{t}^{t-j}\right)\right)\left(1-\delta_{j}\right) Q_{t-j}
$$

where $Q_{t-j}$ is the quantity of new machines started in period $t-j, \Phi\left(z_{t}^{t-j}\right)$ is the idle rate of those machines in period $t$, and $\delta_{j}$ reflects the fact that a subset of machines has failed completely. Aggregate final output, $Y_{t}$ is

$$
Y_{t}=\sum_{j=1}^{M}\left(1-\Phi\left(z_{t}^{t-j}-\sigma\right)\right)\left(1-\delta_{j}\right) Q_{t-j} X_{t-j} .
$$

In the absence of government spending or other uses of output, aggregate consumption, $C_{t}$, satisfies

$$
C_{t}=Y_{t}-k_{t} Q_{t},
$$

where $k_{t} Q_{t}$ is gross investment in new capital machines.

\footnotetext{
${ }^{10}$ If the cost of a machine exceeds the value of a machine for all admissible values of $k_{t}$ no investment is undertaken.
} 


\subsection{Preferences}

To close the model, we specify the economic relationships that determine labor supply and savings decisions. We assume that the economy is made up of representative households whose preferences are given by

$$
\frac{1}{1-\gamma} E_{t} \sum_{s=0}^{\infty} \beta^{s}\left(\frac{C_{t+s}\left(N_{t+s}-L_{t+s}\right)^{\psi}}{N_{t+s}}\right)^{1-\gamma},
$$

where $\beta \in(0,1), \gamma>0, \psi>0$, and $N_{t}=N_{0}(1+n)^{t}$ is the household's growing time endowment. ${ }^{11}$ Households optimize over these preferences subject to the standard intertemporal budget constraint. We assume that claims on the profit streams of individual machines are traded; in equilibrium, households own a diversified portfolio of all such claims.

The first-order condition with respect to consumption is given by

$$
U_{c, t}=\frac{\beta}{1+n} E_{t} R_{t, t+1} U_{c, t+1},
$$

where $U_{c, t+s}$ denotes the marginal utility of consumption. The first-order condition with respect to leisure and work is given by

$$
U_{c, t} W_{t}+U_{L, t}=0
$$

where $U_{L, t}$ denotes the marginal utility associated with an incremental increase in work (decrease in leisure). This completes our description of the economy.

The rational expectations equilibrium is defined to be the set of sequences of prices and quantities such that each household and firm solves its respective maximization problem as described above, taking prices as given, and all markets clear. The derivation of the deterministic steady state and its properties are found in Gilchrist and Williams (1998b). In conducting the dynamic analysis we focus on deviations from the balanced growth path. The solution methodology for the dynamic analysis is described in the appendix.

\section{Model Dynamics}

In this section we describe the model's implications for business cycle and mediumrun dynamics in response to persistent shocks to factor prices; in the next section

\footnotetext{
${ }^{11}$ We also considered the case of indivisible labor as in Hansen (1985) and Rogerson (1988). This specification alters the magnitude of the dynamic responses reported below but not the qualitative properties of the model.
} 
we turn our attention to permanent technology shocks. The purpose of this analysis is not to argue for a specific theory of business cycles based on particular shocks, but instead to document the putty-clay model's dynamic properties and their correspondence to those evident in the data for a wide variety of shocks. For the purpose of comparison, we construct a neoclassical model of vintage capital, initially introduced by Solow (1962). Details of this model are provided in the appendix. In the vintage model, the restriction that ex post capital-labor ratios are fixed is removed. Thus, this model takes the standard Cobb-Douglas putty-putty formulation. The two models are otherwise identical.

We focus primarily on three key business cycle properties: comovement, persistence, and asymmetries. First, as emphasized by Lucas (1977), a fundamental feature of the business cycle is that output movements across sectors exhibit positive comovement. The real business cycle literature tends to focus on a particular interpretation of comovement that is based almost exclusively on a model's implications for unconditional second moments of filtered data; see, for example, Kydland and Prescott (1991). Rotemberg and Woodford (1996) extend the notion of comovement to the forecastable components of output, hours, and consumption. Using a VAR model, they document that the forecastable components of these variables also exhibit strongly positive comovement. Second, Cogley and Nason (1995) document that output growth displays significant positive serial correlation; that is, output growth is persistent. Finally, there is a wide range of evidence that asymmetries exist with respect to the business cycle and the dynamic response to particular shocks. As documented below, the putty-clay model possesses a powerful internal propagation mechanism that yields dramatic improvements over the neoclassical model in all three dimensions.

\subsection{The Short-Run Aggregate Supply Curve}

Insight into the dynamic responses of the putty-clay model is provided by the shortrun aggregate supply curve (the inverse of the marginal product of labor). Here, short-run refers to the time period during which the capital stock is fixed. Figure 2 shows the short-run aggregate supply curve, computed as the markup $1 / W$, in $\log$ deviations from the deterministic steady state, for the neoclassical vintage model and three versions of the putty-clay model with different degrees of idiosyncratic uncertainty (measured by $\sigma$ ). For the neoclassical vintage model, the production 
Figure 2: Short-run Aggregate Supply Curve

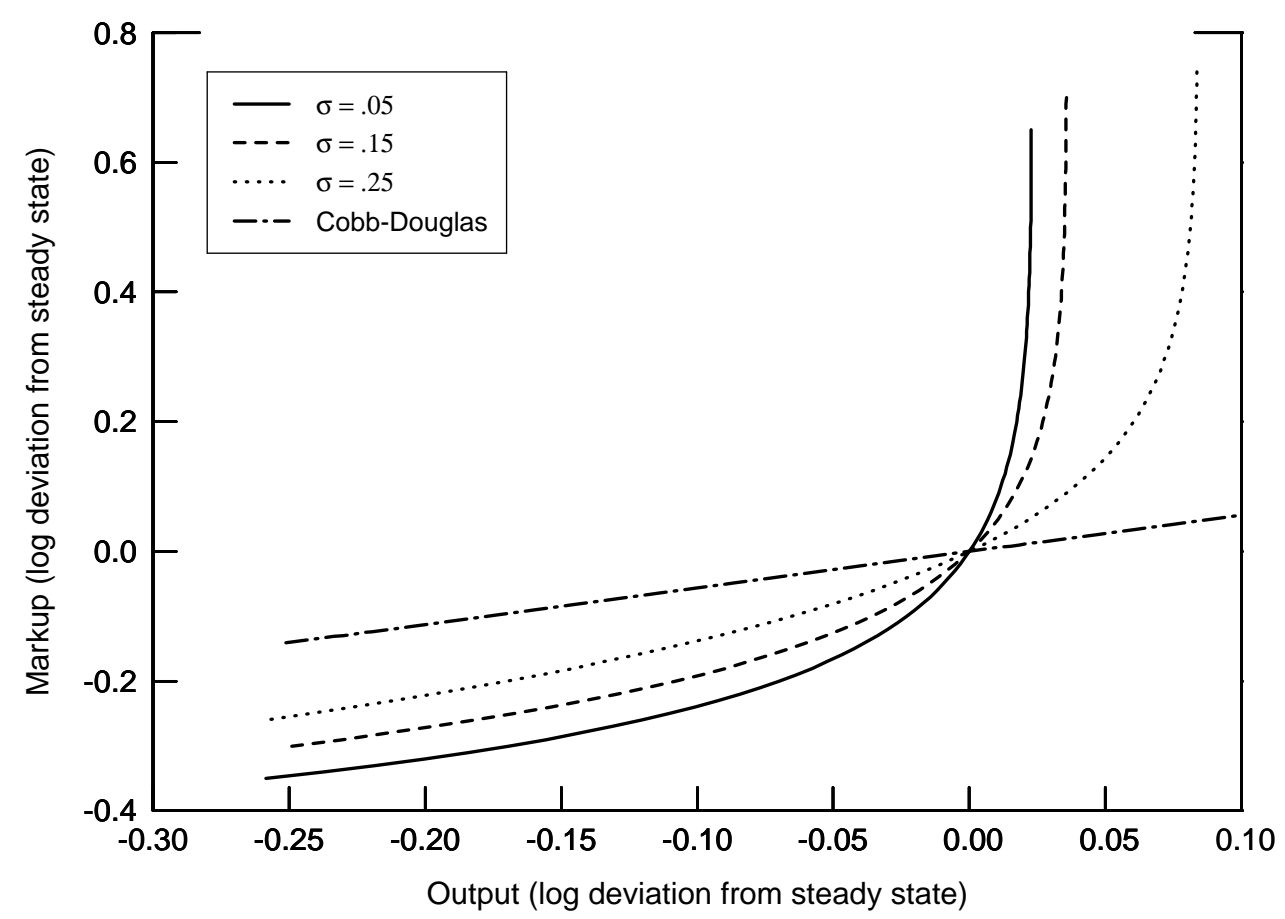

function is Cobb-Douglas implying that the SRAS is linear in logs. The SRAS of the putty-clay model, however, is distinctly nonlinear. For very low values of $\sigma$, the putty-clay SRAS curve becomes vertical for levels of output a few percent above steady state. As $\sigma$ increases, the SRAS curve of the putty-clay model becomes less sharply curved and approaches that of the neoclassical vintage model as $\sigma$ approaches infinity. Thus, the model developed in this paper embeds both the reverse-L shaped aggregate supply curve traditionally associated with putty-clay technology and the log-linear aggregate supply curve of the neoclassical production function. The degree of idiosyncratic uncertainty determines the extent to which the model's short-run aggregate production function and dynamic responses are more putty-clay or neoclassical in flavor.

In the putty-clay model, the variable slope of the SRAS curve results from varying utilization rates of existing machines. Variable utilization is often suggested as an explanation for the fact that empirical estimates of the short-run elasticity of production with respect to labor inputs, $\frac{d \ln Y}{d \ln L}$, are much closer to unity than to labor's 
share. ${ }^{12}$ The intuition here is that a $1 \%$ increase in labor effectively causes a $1 \%$ increase in capital, through increased utilization, and hence a $1 \%$ increase in output. This simple calculation relies on the assumption that capital goods are homogenous however. It also ignores equilibrium determinants of utilization and capacity. In the putty-clay model, $\frac{d Y}{d L}=w$ where $w$ is the efficiency of the marginal machine. As labor inputs increase, the quality of the marginal machine falls, guaranteeing $\frac{d \ln (Y)}{d \ln (L)}<1$.

By considering optimal capacity choice, we can explicitly quantify $\frac{d \ln (Y)}{d \ln (L)}$. In steady state, the short-run elasticity of output with respect to labor for the puttyclay model equals $1-\alpha$, the long-run labor share. If utilization rates rise above steady-state, costs increase rapidly and $\frac{d \ln Y}{d \ln L}<1-\alpha$. The only way to justify $\frac{d \ln Y}{d \ln L}>1-\alpha$ is to argue that firms frequently hold costly excess capacity. This is sub-optimal from the firm's point of view however. Hence, except in response to large negative shocks, firms typically operate in a region where $\frac{d \ln Y}{d \ln L} \simeq 1-\alpha$, and variable utilization does not provide measured short-run increasing returns to labor in the putty-clay model.

Besides having important implications for utilization rates and their influence on labor productivity, the variable slope of the putty-clay SRAS also implies that dynamic responses to positive shocks differs from those to negative shocks, as discussed below. Although not examined here, the nonlinear aggregate supply curve also implies asymmetries in price adjustment in models with nominal rigidities.

\subsection{Calibration}

The models are calibrated using parameter values taken from Christiano and Eichenbaum (1992) and Kydland and Prescott (1991), except for the trend growth rates, which are averages over $1954-96 .{ }^{13}$ We assume a period is one quarter of one year. In annual basis terms, the calibrated parameters are $\beta=0.97, \rho=1, \psi=3, g=$ $0.018, n=0.015, \delta=0.084, \alpha=0.36, M=\infty$. The results reported in this paper are not sensitive to reasonable variations in these parameters. When calibrating the model, the only parameter for which we do not have a prior estimate is the variance of the idiosyncratic component of a machine's productivity, $\sigma^{2}$. As

\footnotetext{
${ }^{12}$ Basu and Fernald (1997) provide a recent discussion.

${ }^{13}$ These estimates are obtained from long-run restrictions, and, with one caveat, are therefore valid for both the putty-clay model and the neoclassical model. The caveat is that variation in $\sigma$ has a small impact on steady-state properties through endogenous depreciation. Endogenous depreciation alters the estimated $\delta$ by $1-2 \%$ and has only a very minor effect on model properties.
} 
discussed above, for large $\sigma$, the short-run aggregate supply curve is very close to Cobb-Douglas. By lowering $\sigma$ we increase the curvature of the short-run aggregate supply curve and increase the degree to which the model displays dynamics unique to the putty-clay structure. To make clear distinctions between the neoclassical and putty-clay models we set $\sigma=0.15$. Lowering $\sigma$ to 0.1 does not alter model results in any substantial manner; lowering $\sigma$ much further causes numerical problems for the dynamic solution methods. On the other hand, raising $\sigma$ to 0.5 for almost all essential purposes replicates the neoclassical model dynamics, while intermediate values $(\sigma=0.2-0.25)$ provide results that are a combination of the neoclassical and putty-clay model with low $\sigma$.

\subsection{Capital Cost Shocks}

We start by characterizing the effect of a temporary but persistent shock to the cost of producing capital goods relative to consumption goods. This is identical to an increase in technology embodied in capital goods; henceforth, we describe it as such. ${ }^{14}$ We assume that embodied technology follows the process $\left(1-\rho_{\theta} L\right) \ln \theta_{t}=$ $\left(1-\rho_{\theta} L\right) t \ln (1+g)+u_{t}$, where $u_{t}$ is an i.i.d. innovation and $L$ is the lag operator. We set the autocorrelation coefficient of the shock process at $\rho_{\theta}=0.95$ implying a half life for the shock of just under 14 quarters.

Figure 3 shows the impulse response function to output for both the putty-clay model (upper panel) and the neoclassical model (lower panel) to a one percentage point positive shock to embodied technology. The difference in output dynamics between the two models is striking. For the putty-clay model, output rises very little initially, steadily increases for a period of five years, and eventually returns to steady state. For the neoclassical model, the peak response occurs at the onset of the shock, after which output exhibits something close to exponential decay as it returns to steady state. In the neoclassical model, output dynamics simply mirror shock dynamics with no evidence of any interesting cyclical pattern. In the puttyclay model, output exhibits a clear "hump-shaped" response that creates a slowly unfolding and long-lasting business cycle.

Figure 3 also plots the impulse response of the Solow residual, conventionally measured, for the putty-clay and neoclassical models. In both models, movements in

\footnotetext{
${ }^{14}$ It is, not, however, the same as a distortionary shock to the cost of capital goods from a change in taxes or that might result from a monetary disturbance in a model with nominal rigidities. Such shocks affect the equilibrium allocation but not the feasible allocation for the economy.
} 
Figure 3: Persistent Cost of Capital Shock

Figure 3: Persistent Cost of Capital Shock

Putty-Clay Model

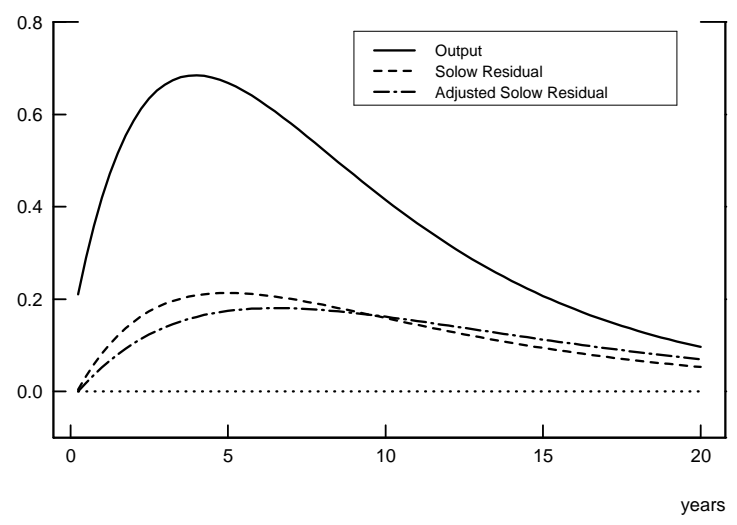

Neoclassical Model

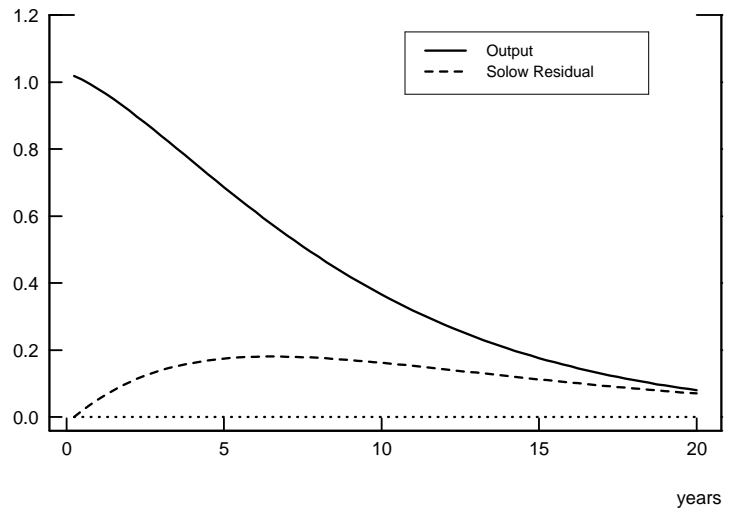

the Solow residual are much smaller (by a factor of 3 to 5 ) than movements in output. Hence, in both models, embodied technological change provides "magnification" as usually measured by movements in output vis-a-vis the Solow residual. In addition to magnification, the putty-clay model provides significant positive comovement, in levels and growth rates, between output and the Solow residual over the cycle. This positive comovement stems from the fact that both output and the Solow residual exhibit similar hump-shaped responses to embodied technological change. In the neoclassical model, embodied shocks generate a negative correlation between growth in output and the Solow residual over the first five years.

The third line in the top panel of figure 3 shows the Solow residual, after correcting for capital utilization. Initially, consistent with the arguments made above, 
Figure 4: Persistent Cost of Capital Shock

Putty-Clay Model

Investment

Labor

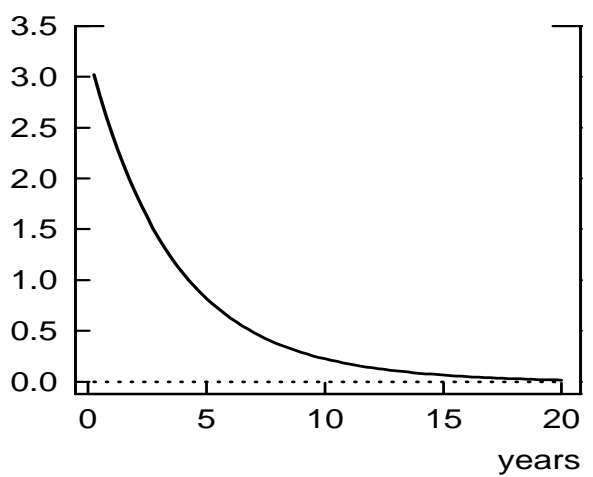

Q

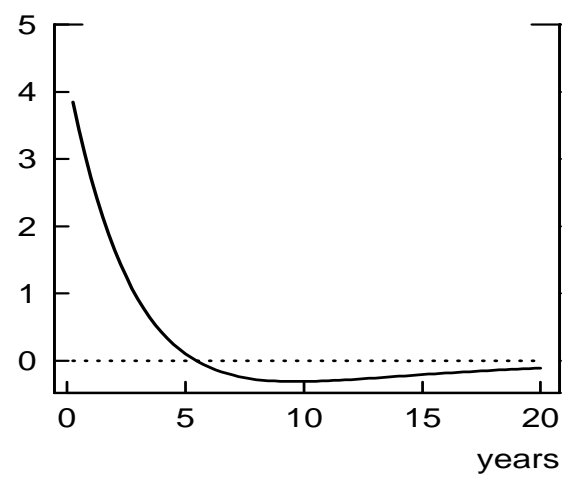

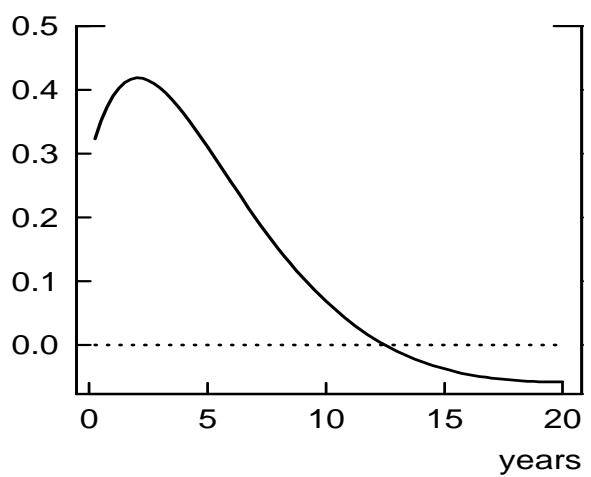

$\mathrm{k}$

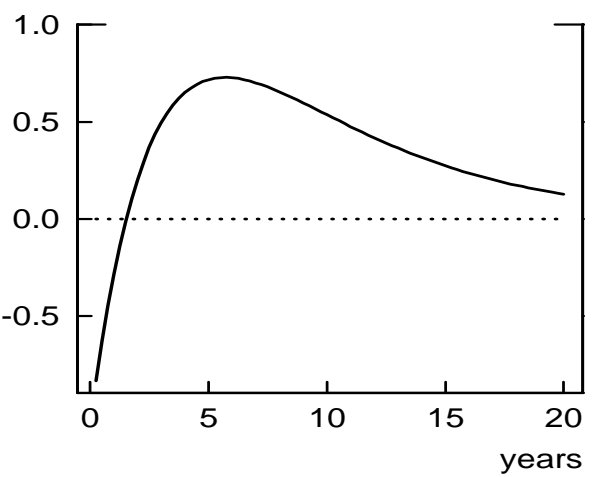

the correction has only a trivial effect on the Solow residual. Over time, we see a somewhat larger adjustment, but this adjustment reflects expanded capacity that lowers the utilization rate of existing machines in later periods.

The upper panels of Figure 4 show the responses of investment and labor hours in the putty-clay model to the same shock. Investment rises immediately as the economy seeks to build new capital goods that embody the latest technology. Hours increase and consumption falls in response to high real interest rates. The initial expansion in hours is muted, however, owing to the sharply increasing short-run aggregate supply curve embedded in the putty-clay model. As more capital is brought 
on line, the short-run supply curve shifts out and labor expands further. As a result, the peak labor response occurs three years after the onset of the shock.

The slow but sustained rise in hours above steady-state levels occurs because the benefits to building new capital goods are much greater if existing, efficient capital is not scrapped in the process. With ex post Leontief technology, labor cannot be reallocated across machines to equate marginal products. To benefit from new machines without losing the productive services of existing capital, the economy must hire new workers to operate these machines. Hence, as new machines become operative, more labor is hired. Eventually, as the productive value of these machines falls, labor returns to steady state. We refer to this dynamic linkage between labor and machines as the putty-clay effect.

Decomposing the investment dynamics into the quantity of new machines, $Q$, and the capital intensity of each new machine, $k$, adds further insight into the model's dynamics. As shown in the lower panels of Figure 4, at the onset of the shock, $Q$ rises and $k$ falls as a large number of low capital-intensity machines are produced. This rapid expansion of inexpensive (in terms of foregone consumption) machines shifts the short-run aggregate supply curve to the right and facilitates the increase in labor input. This reliance on low efficiency capital does not persist, however. As the real interest rate falls and the real wage rises, firms substitute into high capital-intensity capital goods.

The capital-intensity of new machines remains at elevated levels for a number of years as households store the benefits of the temporary shock through increased saving implying capital deepening. Rising capital intensities dramatically offset the exponential rate of decay in technology and consequently provide a sustained increase in the efficiency levels of new machines for a number of years after the shock has occurred. ${ }^{15}$ Because machines are long-lived, this sustained increase in efficiency levels of new machines translates into a sustained increase in total labor productivity over a long horizon.

\footnotetext{
${ }^{15}$ In the initial period, $\theta_{t}$ is $1 \%$ above steady state while $k$ is $1.3 \%$ below steady state, implying that $x=\theta k^{\alpha}$, the mean efficiency of new machines, is $0.75 \%$ percent above steady state. Six years later $\theta$ is $0.3 \%$ above steady state while $k$ is $1.1 \%$ above steady state, implying that $x$ is still $0.7 \%$ above steady state.
} 


\subsection{Labor Cost Shocks}

We now consider the effect of a temporary but highly persistent shock to the marginal cost of labor. This shock may be interpreted as either a reduction in the tax on wage income or a shock to preferences that reduces the marginal utility of leisure relative to the marginal utility of consumption. Formally, we specify the labor cost shock $\ln \eta_{t}=\rho_{\eta} \ln \eta_{t-1}+e_{t}$, where $e_{t}$ is an i.i.d. innovation, and set $\rho_{\eta}=0.98$. We embed $\eta_{t}$ in the labor-leisure first-order condition given by equation 9. Figure 5 shows the responses of output, hours, and consumption to a one percentage point reduction in the marginal cost of labor for the two models. The hump-shaped response of output and hours in the putty-clay model observed in response to the capital cost shock carries over to the labor cost shock.

The labor cost shock illustrates the ability of the two models to generate comovement between output, hours, and consumption. As seen in the figure, this comovement is especially strong in the putty-clay model after the initial shock period and is therefore present in the forecastable components. That is, starting from the first period, output, hours and consumption are rising for a number of years, after which time they decline in unision. The comovement is much weaker in the neoclassical model, especially during the first five years following the onset of the shock. Moreover, what little positive comovement does occur during this period is mostly unforecastable. While consumption is rising over several years, hours and output are falling, making the forecastable comovement between consumption and the other two series negative rather than positive.

\subsection{Nonlinear Dynamics}

The degree of curvature embedded in the short-run aggregate supply curve plays an important role in conditioning the putty-clay model's response to shocks. For small shocks such as those discussed above, the magnitude of the response to positive and negative shocks is roughly the same. As we consider larger disturbances, the curvature of the short-run aggregate supply curve away from steady-state becomes important, and the model's dynamic responses display interesting asymmetries. In particular, the model delivers the result that a response to negative shocks is more rapid and larger than that to positive shocks. This is consistent with the evidence on the response to monetary shocks documented by Cover (1992) and that to oil price shocks studied by Tatom (1988) and Mork (1989). In a business cycle context, this 
Figure 5: Persistent Cost of Labor Shock

Putty-Clay Model

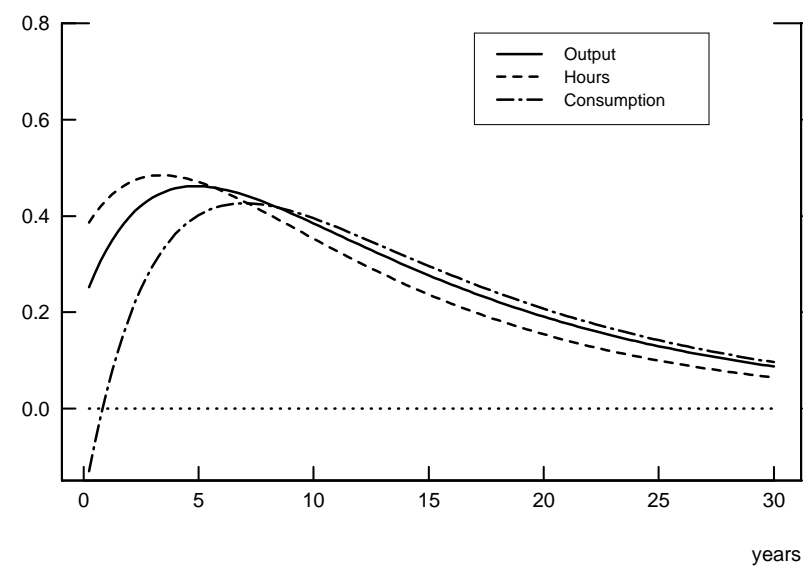

Neoclassical Model

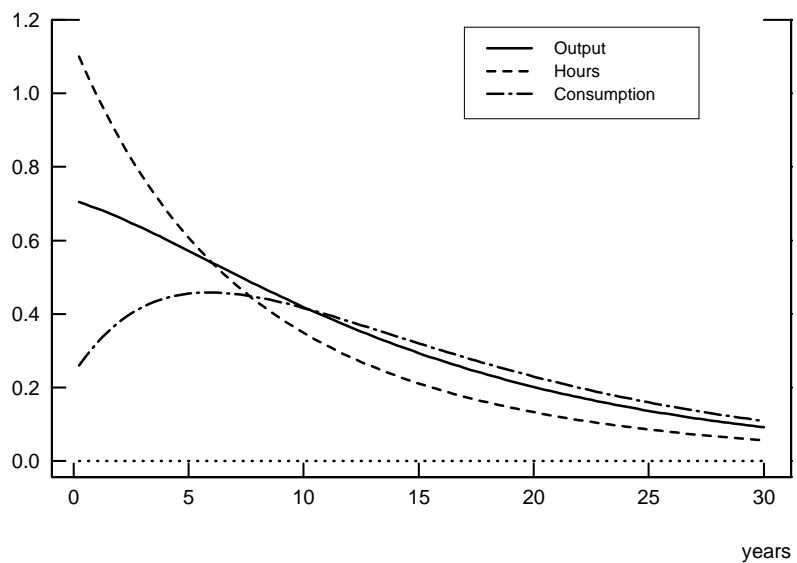

pattern of asymmetric responses can imply that recessions are deeper and steeper than expansions, a result consistent with the time series evidence documented by Neftci (1984), Sichel (1993), and Potter (1995).

For the type of shocks considered here, the most likely source of large shocks in an economy such as the U.S. come through changes in tax policy that affect factor prices. ${ }^{16}$ An investment tax credit or a revision in personal income tax rates are plausible sources of persistent movements in factor costs of $10 \%$ or more. To display the model's ability to generate asymmetries, we therefore consider the differential

\footnotetext{
${ }^{16}$ Other potential sources of large shocks are energy prices and monetary disturbances.
} 
Figure 6: Asymmetries in Response to Labor Cost Shocks*

Labor

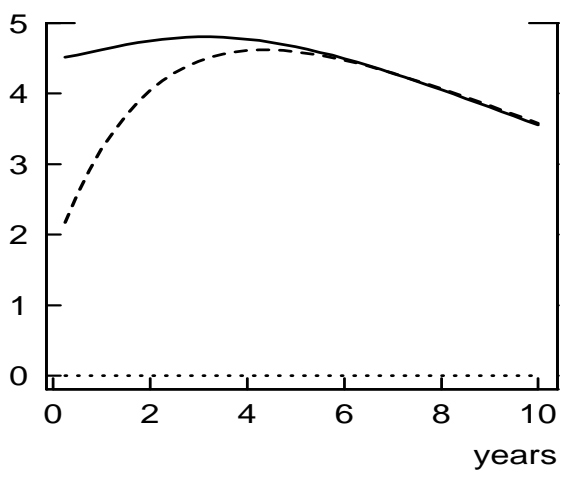

Consumption

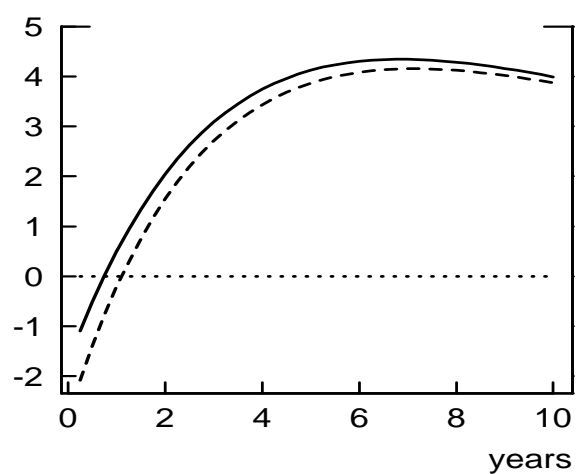

Output

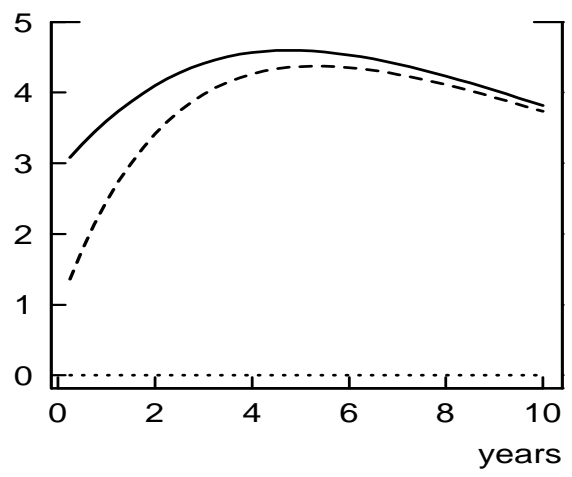

Investment

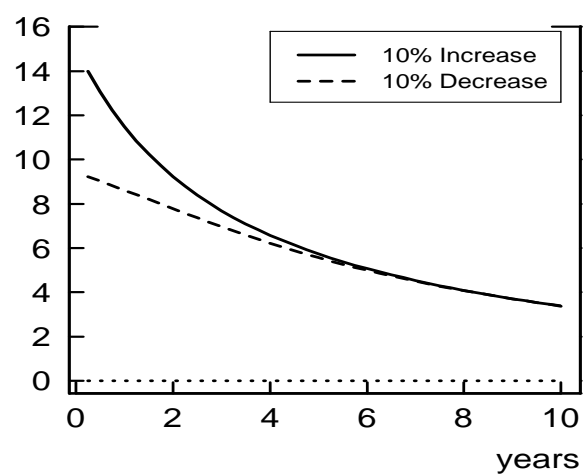

* Impulse Responses to 10\% Increase in Cost of Labor Displayed with Reverse Sign

effect of a $10 \%$ increase versus decrease in the labor cost shock considered above.

The results reported in Figure 6 reveal the basic source of the asymmetry. A labor cost increase causes an immediate shutdown of machines as the economy moves down the relatively flat portion of the short-run aggregate supply curve. This immediate shutdown produces a sharp contraction in output and hours in both the initial and subsequent periods. Owing to the shutdown, the economy has excess machine capacity, and investment drops sharply in response to the shock. In contrast, a labor cost decrease has little immediate effect on either output or hours as the economy is pushed up the steep portion of the short-run aggregate supply curve. 
Evidence of non-linearity only disappears after 6-8 years as capacity eventually adjusts. As a result, in the putty-clay model, large contractionary shocks cause steep immediate declines in output and hours while large expansionary shocks generate a hump-shaped dynamic response even more pronounced than in the case of small expansionary shocks. Of particular interest here is the fact that the asymmetries on labor are the most pronounced, a result supported by Neftci (1984)'s non-linear time series analysis.

\section{Permanent Technology Shocks}

An important unresolved issue in macroeconomics is the extent to which permanent innovations in technology can explain output fluctuations at the business cycle frequency. While past research has claimed varying degrees of success, more recent work has tempered enthusiasm for business cycle theories based on permanent technology shocks. Cogley and Nason (1995) and Rotemberg and Woodford (1996) demonstrate that the standard neoclassical model with permanent disembodied productivity shocks is unable to match the persistence and comovement properties of key aggregate variables. Christiano and Eichenbaum (1992) show that such models predict excessive contemporaneous correlation between output growth and laborproductivity growth. In this section, we extend this literature in two directions by analyzing the effects of permanent embodied, as well as disembodied, technology shocks and allowing for putty-clay technology. Greenwood et al. (1997) argue that the evidence supports embodied technology as the primary source of technological change, making the analysis of such shocks of particular interest. As shown below, the putty-clay model generates dynamic responses to permanent technology shocks that accord well with key properties of the data.

We begin with an analysis of the persistence properties of the two models. The first row of table 1 shows the unconditional autocorrelation of output growth for the two models for each type of technology shock. ${ }^{17}$ For comparison, this statistic is estimated to be 0.3 in the data. An alternative measure of persistence, emphasized by Rotemberg and Woodford (1996), is the ratio of standard deviations of forecastable output growth to total output movements. The second and third rows of the table report this statistic at the four- and eight-quarter horizons. For comparison, these

\footnotetext{
${ }^{17}$ All model moments reported in this paper are computed using the linearized model.
} 
Table 1: Output Persistence with Permanent Technology Shocks

\begin{tabular}{l|cc|cc}
\hline \hline & \multicolumn{2}{|c|}{ Neoclassical Model } & \multicolumn{2}{c}{ Putty-clay Model } \\
& Disembodied & Embodied & Disembodied & Embodied \\
\hline \multirow{2}{*}{$\operatorname{cor}\left(\Delta y_{t}, \Delta y_{t-1}\right)$} & 0.01 & 0.07 & 0.03 & 0.80 \\
& & & & 0.14 \\
$\sigma_{\Delta \hat{y}_{t, 4} / \sigma_{\Delta y_{t, 4}}}$ & 0.06 & 0.25 & 0.17 & 0.77 \\
$\sigma_{\Delta \hat{y}_{t, 8}} / \sigma_{\Delta y_{t, 8}}$ & 0.08 & 0.3 & 0.17 \\
\hline \multicolumn{2}{l}{ Notes: Shocks are permanent. y denotes the log of output. $\Delta \hat{y}_{t, j}=$} \\
$E_{t}\left(y_{t+j}-y_{t}\right)$, where expectations are based on date $t$ information. All \\
reported moments are asymptotic means. \\
\hline
\end{tabular}

are estimated to be about $0.6-0.7$ in the data.

Two results stand out clearly in table 1. First, the putty-clay model delivers significantly more persistence in output growth (by either measure and for either type of permanent technology shock) than the neoclassical model. Second, embodied technology shocks generate much more persistence in output growth than disembodied shocks. This is especially true for the putty-clay model, which, when driven solely by permanent embodied technology shocks, actually overpredicts the persistence in output growth observed in U.S. post war data.

The intuition behind these results is provided by the impulse responses to permanent technology shocks, plotted in Figure 7. In both the putty-clay and neoclassical models, the long run effect of a $1-\alpha$ percentage increase in technology is to raise output, consumption and investment by $1 \%$ while leaving the long-run level of labor unchanged. In the case of disembodied shocks (shown in the panels on the right) total factor productivity increases immediately, causing an immediate expansion of output. This initial increase in output represents a large fraction of the permanent increase. As a result, for both the neoclassical and putty-clay models, nearly all of the output dynamics are unforecastable, and output growth displays very little persistence in response to disembodied shocks to technology.

If technology shocks are embodied in capital (shown in the panels on the left) total factor productivity does not increase until the economy invests in new capital goods. In the neoclassical model, a positive shock to embodied technology still causes a large immediate expansion in output as hours surge in response to the high 
Figure 7: Permanent Productivity Shocks

Embodied Technology Shock

Output

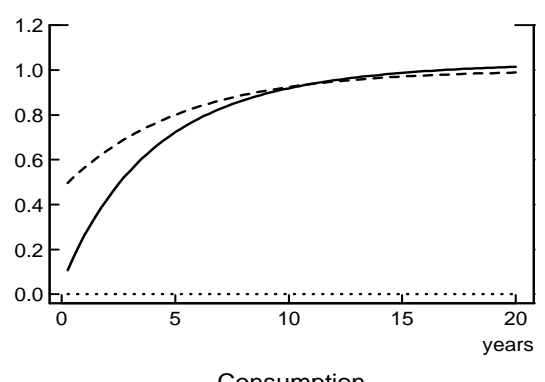

Consumption
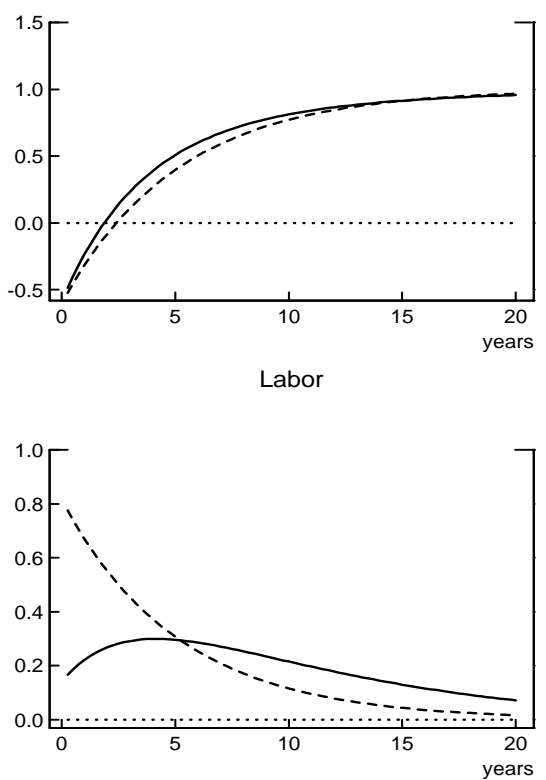

Disembodied Technology Shock

Output
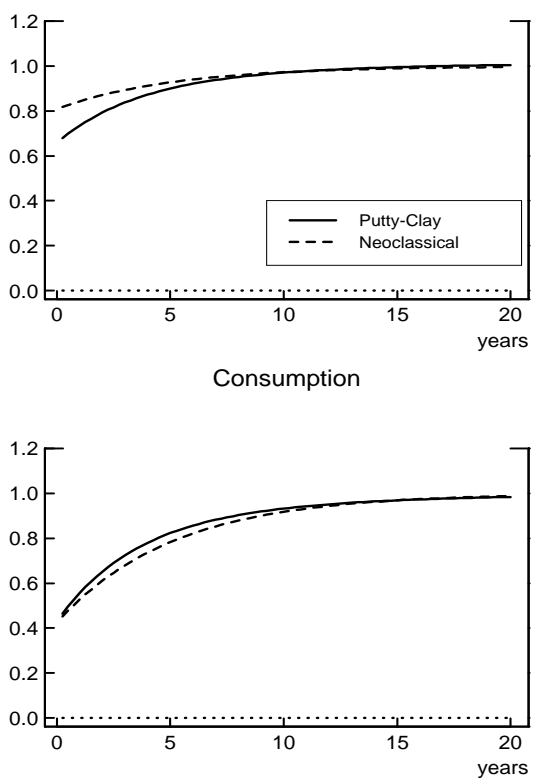

Labor

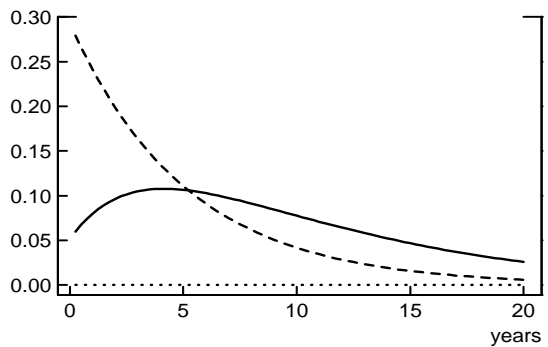

rate of return to investment. Because of the rapid expansion in production, the initial output response represents a large fraction of the permanent response and output movements are mostly unpredictable. In the putty-clay model, a positive shock to embodied technology causes only a small initial expansion despite the increased desire for new investment, owing to the high costs of expanding production in the short-run. Both output and hours expand slowly as new capital is brought on-line, with labor reaching its peak response a number of years after the shock occurs. As a result, most of the output dynamics are predictable and output growth displays a high degree of persistence in response to embodied shocks to technology. 
Table 2: Forecastable Comovement Between Output and Hours

\begin{tabular}{l|cc|cc}
\hline \hline & \multicolumn{2}{|c|}{ Neoclassical Model } & \multicolumn{2}{c}{ Putty-clay Model } \\
& Disembodied & Embodied & Disembodied & Embodied \\
\hline & & & & \\
$\operatorname{cor}\left(\Delta \hat{h}_{t, 4}, \Delta \hat{y}_{t, 4}\right)$ & -1.00 & -1.00 & 0.44 & 0.44 \\
$\operatorname{cor}\left(\Delta \hat{h}_{t, 8}, \Delta \hat{y}_{t, 8}\right)$ & -1.00 & -1.00 & 0.28 & 0.28 \\
& \multicolumn{4}{l}{} \\
\hline
\end{tabular}

In addition to the limited degree of internal propagation, Rotemberg and Woodford (1996) criticize the high negative correlations between predictable movements in output and hours implied by the standard neoclassical model in response to random walk technology shocks. Table 2 formalizes this point by reporting the correlation between forecastable growth of output and hours four and eight quarters ahead. For comparison, these correlations are estimated to be about 0.86 in the data. For the neoclassical model, the negative correlation follows from the fact that the peak response in hours occurs at the onset of the shock while output continues to grow as capital accumulation proceeds. Thus, while hours are falling in a predictable fashion, output is rising in a predictable fashion. The putty-clay model's slow expansion of output and hours reverses this correlation and provides a closer match with the data on this dimension.

Finally, we consider the models' predictions regarding the contemporaneous correlation between output and productivity growth. Table 3 reports this correlation for the two models for each of the two sources of permanent productivity shocks. For comparison, this correlation is estimated to be 0.76 in the data. If hours were held constant, both models would predict a perfectly positive correlation between growth in output and productivity. With disembodied shocks, this correlation is nearly unity as the effect of the movements in hours on productivity are dwarfed by the effects of the shock itself.

In the case of embodied technology shocks, the models' predictions differ greatly. The neoclassical model predicts a highly negative correlation between growth in output and productivity. This negative correlation results from the immediate expansion of hours which produces a large decline in productivity at the same time as the largest increase in output. The putty-clay model, on the other hand, predicts 
Table 3: Output and Productivity Growth Comovement

\begin{tabular}{l|cc|cc}
\hline \hline & \multicolumn{2}{|c|}{ Neoclassical Model } & \multicolumn{2}{c}{ Putty-clay Model } \\
& Disembodied & Embodied & Disembodied & Embodied \\
\hline \multirow{2}{*}{$\left.\operatorname{cor}\left(\Delta y_{t}, \Delta p_{t}\right)\right)$} & 0.99 & -0.71 & 1.00 & 0.50 \\
& \multicolumn{4}{l}{} \\
\hline
\end{tabular}

a positive correlation between output and productivity growth. This difference lies in the muted expansion of hours, which does less to offset the positive comovement in productivity and output directly resulting from the shock. The putty-clay model thus provides an explanation for why the correlation between growth in output and productivity may be positive but less than unity, even in the absence of shocks to demand.

Although embodied shocks help explain a number of empirical regularities, some results are not consistent with the business cycle. In particular, both the neoclassical and putty-clay models create excess volatility of consumption and investment relative to the data (as seen in the set of moments reported in the appendix). This excess volatility occurs because factor cost movements create investment patterns that overwhelm the usual desire to smooth consumption.

\section{Estimation}

The results in the previous section highlight the putty-clay model's ability to explain key business cycle facts such as persistence in output growth and positive predictable comovement between output and hours. In this section we provide a more formal evaluation of the empirical relevance of a putty-clay production process in matching key moments of U.S. aggregate data.

To perform this evaluation, we construct a two-sector model that nests both the putty-clay model and the neoclassical model within the same econometric framework. Letting $\theta_{t}$ denote the level of technology embodied in capital, we assume that sector 1 output is derived from the putty-clay production process describe above, while sector 2 output is derived from the Solow vintage-capital model described in the appendix. Letting $A_{t}$ denote the level of disembodied technology, we assume 
that final-goods output is a Cobb-Douglas function of sectoral output:

$$
Y_{t}=A_{t} Y_{1 t}^{\lambda} Y_{2 t}^{1-\lambda}
$$

We then estimate $\lambda$, the share of output obtained from the putty-clay sector. If our estimate of $\lambda$ is close to unity, the data effectively put a large weight on puttyclay production in order to match the vector of moments that we consider. If our estimate of $\lambda$ is close to zero, the data suggest little if any role for putty-clay in explaining the moments we choose to match.

To address recent criticisms regarding standard RBC-style moment-matching exercises, our methodology relies on both unconditional moments traditionally emphasized in the RBC literature and conditional moments emphasized by Rotemberg and Woodford (1996). ${ }^{18}$ The unconditional moments include the standard deviations of (the growth rates of) investment and hours relative to the standard deviation of output, the correlations of investment and hours with output, and the first-order autocorrelations of these variables. The conditional moments include correlations and regression coefficients among predictable changes in output, investment and hours over a four-quarter horizon. ${ }^{19}$ These moments also include the ratio of the standard deviation of the predictable change in output relative to the standard deviation of the total change in output at this horizon.

To compute moments constructed from predictable components we specify a VAR process for $\left(y_{t}, h_{t}, i_{t}\right)$, the logs of output, hours, and investment in the data. ${ }^{20}$ As shown in the appendix, the statistical properties and hence all relevant moments of this VAR are summarized by an unknown parameter vector $\xi$. We estimate $\xi$ using standard time-series techniques and then use the resulting parameter estimate to compute a set of moments $g(\hat{\xi})$, along with the variance of these moments $V_{g}$.

Our estimation strategy is to choose $\lambda$, the share of output accounted for by the

\footnotetext{
${ }^{18}$ Christiano and Eichenbaum (1992) provide a GMM procedure for estimating and evaluating business-cycle models based on unconditional moments. A contribution of this paper is to provide a GMM procedure that allows for both types of moments within a unified econometric framework.

${ }^{19}$ Results using a combination of moments computed from predictable changes at the 4,8 and 16 quarter horizon do not alter our conclusions.

${ }^{20}$ Our investment series is business fixed investment (non-residential equipment and structures). In the model, investment is a linear combination of output and consumption so that consumption and investment contain the same information when combined with output. An alternative approach to the data is to define investment as a linear combination of output and non-durables consumption. Although less desirable for a model explicitly designed to capture short-run capital/labor complementarities we have considered this approach, as well as matching moments computed from total consumption rather than investment. Neither of these alternatives alter our empirical results in any substantial way.
} 
putty-clay sector, along with other relevant parameters, to minimize the distance between model moments and data moments. For a given vector $\psi$ of unknown model parameters, we use our model solution to compute $g_{M}(\psi)$, the model's analog of $g(\xi)$. By minimizing

$$
L(\psi)=\left(g_{M}(\psi)-g(\hat{\xi})\right)^{\prime} V_{g}^{-1}\left(g_{M}(\psi)-g(\hat{\xi})\right)
$$

with respect to $\psi$ we obtain the minimum distance estimator $\hat{\psi}$. For a time-series sample of size $T, T * L(\hat{\psi})$ provides a $\chi^{2}$ test for equality between $g_{M}(\hat{\psi})$ and $g(\hat{\xi})$.

For our moment matching exercise, we consider two independant sources of fluctuations: disembodied technological change and embodied technological change. We assume that shocks follow an AR1 process and then freely estimate $\left[\rho_{A}, \rho_{\theta}\right]$, the autocorrelations of the shock processes, and $\frac{\sigma_{\theta}}{\sigma_{A}+\sigma_{\theta}}$, the relative importance of embodied shocks. To generalize our results beyond technology shocks, we also consider a model that includes labor cost shocks. Under this specification, we also estimate the autocorrelation of labor cost shocks, and the percentage of fluctuations attributable to labor cost shocks.

Estimation results based on unconditional moments reported in table 4 place a large weight on the putty-clay production technology - on the order of $50 \%$ for the model that does not include labor cost shocks. ${ }^{21}$ The estimate of $\frac{\sigma_{\theta}}{\sigma_{A}+\sigma_{\theta}}$ is about 0.2 , suggesting a substantial role for embodied technology shocks in explaining aggregate dynamics. ${ }^{22}$ For comparison purposes, table 4 also reports $h_{M}(\psi)$ and $T * L(\psi)$ for the standard RBC model with disembodied shocks and $\rho_{A}=0.95$. Relative to this baseline, allowing for embodied shocks and a non-zero weight on putty-clay provides a substantial gain in terms of fit, reducing $T * L(\psi)$ by $50 \% .{ }^{23}$. In this specification, the estimated values of $\rho_{A}$ and $\rho_{\theta}$ reach their upper bound of unity, emphasizing the importance of persistent shocks when matching unconditional moments.

Introducing labor cost shocks provides further gains in fit and places even greater emphasis on putty-clay technology. The gain in fit comes from a relatively large fraction of fluctuations being accounted for by labor cost shocks. Our estimation results also set $\rho_{L}$, the autocorrelation of labor cost shocks, at an imposed upper

\footnotetext{
${ }^{21}$ The putty-clay share is estimated precisely with a standard error of about 0.02 .

${ }^{22} \mathrm{As}$ an alternative to estimating $\frac{\sigma_{\theta}}{\sigma_{A}+\sigma_{\theta}}$, we considered fixing this ratio at 0.6 , Greenwood et al. (1997)'s estimate of the share of post-war technological change embodied in capital. Assuming random walk shocks and setting $\sigma_{L}=0$, we estimate a putty-clay share of 0.69 , indicating that our estimate of the putty-clay share is robust to changes in the mix of technology shocks.

${ }^{23}$ Nonetheless, we still reject a test of equality between model and data moments. This may partly reflect the poor small-sample properties of such tests (Burnside and Eichenbaum 1996).
} 
Table 4: Unconditional Moments: Estimation of Two-Sector Model

\begin{tabular}{|c|c|c|c|c|c|}
\hline \multirow{2}{*}{ Model Parameters: } & \multirow{2}{*}{$\begin{array}{l}\text { Neoclassical } \\
\text { Benchmark }\end{array}$} & \multirow{2}{*}{\multicolumn{2}{|c|}{$\begin{array}{c}\text { Two-Sector } \\
\text { Model }\end{array}$}} & \multicolumn{2}{|c|}{ Data } \\
\hline & & & & Est. & S. E. \\
\hline $\begin{array}{l}\text { Putty-Clay Share } \\
\frac{\sigma_{\theta}}{\sigma_{\theta}+\sigma_{A}} 1 \\
\frac{\sigma_{L}}{\sigma_{\theta}+\sigma_{A}+\sigma_{L}} 2 \\
\rho_{\theta} \\
\rho_{A} \\
\rho_{L}\end{array}$ & $\begin{array}{l}0 \\
0 \\
0\end{array}$ & $\begin{array}{c}0.47 \\
0.23 \\
0 \\
1.00 \\
1.00\end{array}$ & $\begin{array}{r}0.67 \\
0.21 \\
0.55 \\
1.00 \\
1.00 \\
0.99^{3}\end{array}$ & & \\
\hline $\begin{array}{l}\text { Moments: } \\
\sigma_{\Delta h} / \sigma_{\Delta y} \\
\sigma_{\Delta i} / \sigma_{\Delta y} \\
\operatorname{cor}\left(\Delta h_{t}, \Delta y_{t}\right) \\
\operatorname{cor}\left(\Delta i_{t}, \Delta y_{t}\right) \\
\operatorname{cor}\left(\Delta y_{t}, \Delta y_{t-1}\right) \\
\operatorname{cor}\left(\Delta h_{t}, \Delta h_{t-1}\right) \\
\operatorname{cor}\left(\Delta i_{t}, \Delta i_{t-1}\right) \\
\text { Minimized Objective: }\end{array}$ & $\begin{array}{l}0.57 \\
2.85 \\
0.99 \\
1.00 \\
-0.02 \\
-0.04 \\
-0.03 \\
708\end{array}$ & $\begin{array}{l}0.39 \\
2.49 \\
0.69 \\
0.87 \\
0.08 \\
0.21 \\
0.07 \\
361\end{array}$ & $\begin{array}{l}0.66 \\
2.39 \\
0.61 \\
0.89 \\
0.12 \\
0.26 \\
0.12 \\
\\
246\end{array}$ & $\begin{array}{l}0.65 \\
1.80 \\
0.74 \\
0.61 \\
0.32 \\
0.61 \\
0.50\end{array}$ & $\begin{array}{l}0.04 \\
0.11 \\
0.04 \\
0.05 \\
0.08 \\
0.06 \\
0.07\end{array}$ \\
\hline $\begin{array}{l}\text { 1. } \frac{\sigma_{\theta}}{\sigma_{\theta}+\sigma_{A}} \text { measures the } \\
\text { 2. } \frac{\sigma_{L}}{\sigma_{\theta}+\sigma_{A}+\sigma_{L}} \text { measures } \\
\text { 3. Estimate constrained }\end{array}$ & $\begin{array}{l}\text { re of techno } \\
\text { relative mas } \\
\text { upper bour }\end{array}$ & $\begin{array}{l}\text { sh } \\
\text { ude } \\
\text { f } 0 .\end{array}$ & $\begin{array}{l}\mathrm{ks} \text { em } \\
\text { labo }\end{array}$ & $\begin{array}{l}\text { died } \\
\text { hark }\end{array}$ & $\begin{array}{l}\text { apital. } \\
\text { ocks. }\end{array}$ \\
\hline
\end{tabular}

bound of 0.99. Thus, even with the introduction of labor cost shocks, our moment matching exercise still places a strong emphasis on highly persistent shocks. Given the importance of all three shocks in the estimation procedure, it is interesting to ask what fraction of output variance is accounted for by each shock. Variance decompositions using estimated parameter values imply that disembodied, embodied and labor cost shocks account for $76 \%, 4 \%$ and $20 \%$ of output fluctuations at the one-year horizon and $63 \%, 11 \%$ and $26 \%$ at the five-year horizon.

Estimation results based on the full set of moments reported in Table 5 also imply a large putty-clay share - on the order of two-thirds, regardless of the shock processes. Introducing putty-clay technology provides substantial gain in fit, which is further improved through the introduction of labor cost shocks. When considering the full set of moments, the estimate of $\frac{\sigma_{\theta}}{\sigma_{A}+\sigma_{\theta}}$ drops from about 0.2 to zero, and the persistence of disembodied shocks falls to 0.94. The drop in $\frac{\sigma_{\theta}}{\sigma_{A}+\sigma_{\theta}}$ is offset 
Table 5: All Moments: Estimation of Two-Sector Model

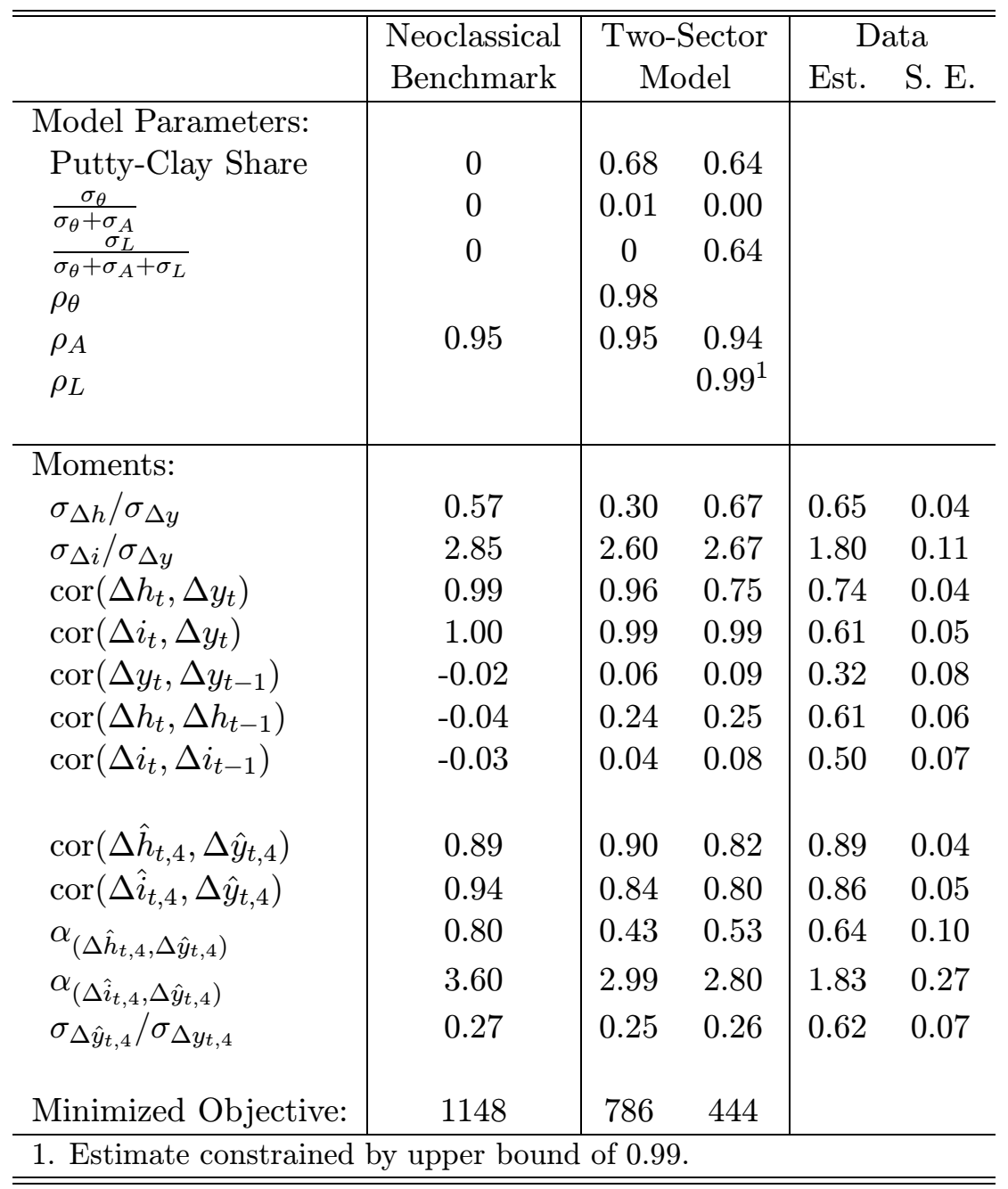

by an increase in the percentage of fluctuations obtained from labor cost shocks. Computing variance decompositions using estimates in Table 5, we find that labor cost shocks account for $15 \%$ of output fluctuations at the one-year horizon, and $47 \%$ at the five-year horizon. These results imply that disembodied shocks to technology do well at explaining output movements at high frequencies, while persistent shocks to factor costs do better at lower frequencies. ${ }^{24}$

\footnotetext{
${ }^{24}$ As robustness checks to our estimation results, we have considered a number of issues, including alternative parameterizations of the utility function and the presence of convex adjustment costs for investment. For estimation based on unconditional moments, lowering the intertemporal elasticity of substitution or adding adjustment costs increases both the putty-clay share and $\frac{\sigma_{\theta}}{\sigma_{\theta}+\sigma_{A}}$. By raising $\gamma$ or introducing adjustment costs, we reduce the volatility of consumption and investment
} 


\section{Conclusion}

By combining investment irreversibilities, capacity constraints, and variable capacity utilization, the putty-clay model developed in this paper provides a rich framework for analyzing a number of issues regarding investment, labor, capacity utilization, and productivity. In this paper we highlight some implications for employment, output, and investment at business cycle and medium-run frequencies. Compared to standard neoclassical models, the putty-clay model displays a substantial degree of persistence and propagation for both output and hours in response to shocks to factor costs and technology. And, unlike standard neoclassical models, the putty-clay model generates forecastable comovements between labor, output, and consumption consistent with the data. Finally, owing to the existence of a nonlinear aggregate supply curve, the putty-clay model generates interesting asymmetries with recessions steeper and deeper than expansions.

Beyond its descriptive appeal, the putty-clay production process is also found to be empirically relevant for explaining business-cycle and medium-run dynamics. Estimates obtained from a two-sector model that minimize the distance between moments generated by the model and those obtained from the data place a sizable weight on putty-clay production - on the order of one-half to three-fourths. This finding is robust to the specification of the shock processes and the choice of moments used in the estimation. In addition to supporting a major role for putty-clay technology, our results suggest that factor price shocks may be key to explaining fluctuations, especially at the medium-run frequencies of two to eight years.

This paper focuses on the effects of factor-cost shocks and technological change for business-cycle dynamics. The putty-clay model developed here has broader applications for fiscal, monetary and trade policy, and the study of transitional dynamics for growing economies. In particular, this paper highlights the notion that the short-run effects of policy may be substantially different from their medium-term consequences, owing to the linkage between the capital accumulation process and labor market dynamics.

in response to movements in factor costs. When considering the full set of moments we find little sensitivity to such specifications. 


\section{References}

Anderson, Gary and George Moore, "A Linear Algebraic Procedure for Solving Linear Perfect Foresight Models," Economics Letters, 1985, 17, 247-252.

Ando, Albert, Franco Modigliani, Robert Rasche, and Stephen Turnovsky, "On the Role of Expectations of Price and Technological Change in an Investment Function," International Economic Review, 1974, 15, 384-414.

Atkeson, Andrew and Patrick J. Kehoe, "Putty-Clay Capital and Energy," August 1994. NBER Working Paper No. 4833.

Basu, Susanto and John G. Fernald, "Returns to Scale in U.S. Production: Estimates and Implications," Journal of Political Economy, 1997, 105, 249-83.

Benhabib, Jess and Aldo Rustichini, "Vintage Capital, Investment and Growth," Journal of Economic Theory, 1991, 55, 323-339.

and _ , "A Vintage Capital Model of Investment and Growth: Theory and Evidence," in Becker R. et al., ed., General Equilibrium, Growth and Trade. II The Legacy of Lionel W. McKenzie, New York: Academic Press, 1993, pp. 248301

Bischoff, Charles W., "The Effect of Alternative Lag Distributions," in G. Fromm, ed., Tax Incentives and Capital Spending, Washington, D.C.: The Brookings Institution, 1971, chapter 3, pp. 61-130.

Blanchard, Olivier J., "The Medium Run," Brookings Papers on Economic Activity, 1997, pp. 89-158.

Boucekkine, Raouf, Marc Germain, and Omar Licandro, "Replacement Echoes in the Vintage Capital Growth Model," Journal of Economic Theory, $1997,74,333-48$.

Bresnahan, Timothy F. and Valerie A. Ramey, "Output Fluctuations at the Plant Level," Quarterly Journal of Economics, 1994, 109, 593-624.

Burnside, Craig and Martin Eichenbaum, "Small Sample Properties of GMM Based Wald Tests," Journal of Business Economics and Statistics, 1996. 
Caballero, Ricardo J. and Mohamad L. Hammour, "On the Timing and Efficiency of Creative Destruction," Quarterly Journal of Economics, 1996, $111,805-52$.

and __ , "Incomplete Contracts, Factor Proportions, and Unemployment," Carnegie Rochester Conference Series on Public Policy, 1998, 48.

_ _ Eduardo Engel, and John Haltiwanger, "Plant-Level Adjustment and Aggregate Investment Dynamics," Brookings Papers on Economic Activity, 1995, pp. 1-54.

Calvo, Guillermo A., "Optimal Growth in a Putty-Clay Model," Econometrica, 1976, 44, 867-878.

Campbell, Jeffrey R., "Technical Change, Diffusion and Productivity," 1994. Mimeo, Rochester University.

Cass, David and Joseph E. Stiglitz, "The Implications of Alternative Saving and Expectations Hypotheses for Choices of Technique and Patterns of Growth," Journal of Political Economy, 1969, 7r, 586-627.

Christiano, Lawrence J. and Martin Eichenbaum, "Current Real-BusinessCycle Theories and Aggregate Labor-Market Fluctuations," American Economic Review, 1992, 82, 430-450.

Cogley, Timothy and James M. Nason, "Output Dynamics in Real Business Cycle Models," American Economic Review, 1995, 85, 492-511.

Cooley, Thomas F., Gary D. Hansen, and Edward C. Prescott, "Equilibrium business cycles with idle resources and variable capacity utilization," Economic Theory, 1995, 6, 35-49.

_ _ Jeremy Greenwood, and Mehmet Yorukoglu, "The Replacement Problem," 1994. Institute for Empirical Macroeconomics Discussion Paper 95.

Cooper, Russel and John Haltiwanger, "The Macroeconomic Implications of Machine Replacement: Theory and Evidence," American Economic Review, 1993, 83, 360-382. 
_ _ _ _ and Laura Power, "Machine Replacement and the Business Cycle: Lumps and Bumps," 1995. NBER Working Paper \#5260.

Cover, James Perry, "Asymmetric Effects of Positive and Negative Money-Supply Shocks," Quarterly Journal of Economics, 1992, 107, 1261-1282.

Doms, Mark and Timothy Dunne, "An Investigation into Capital and Labor Adjustment at the Plant Level," 1993. Mimeo, Center for Economic Studies, Bureau of the Census.

Fair, Ray C. and John B. Taylor, "Solution and Maximum Likelihood Estimation of Dynamic Nonlinear Rational Expectations Models," Econometrica, July 1983, 51 (4), 1169-1185.

Gilchrist, Simon and John C. Williams, "Cutting Models Down to Size: Efficient Methods for Solving Large Rational Expectations Models," 1998. Mimeo, Board of Governors of the Federal Reserve.

_ and _ _ "Putty-Clay and Investment: A Steady State Analysis," 1998. Mimeo, Board of Governors of the Federal Reserve.

Greenwood, Jeremy, Zvi Hercowitz, and Per Krusell, "Long-Run Implications of Investment-Specific Technological Change," American Economic Review, 1997, pp. 342-362.

Hamilton, James D., Time Series Analysis, Princeton University Press, 1994.

Hansen, Gary, "Indivisible Labor and the Business Cycle," Journal of Monetary Economics, 1985, 16, 309-327.

Johansen, Leif, "Substitution versus Fixed Production Coefficients in the Theory of Economic Growth: A Synthesis," Econometrica, 1959, 27, 157-176.

Johnson, Norman L., Samuel Kotz, and N. Balakrishnan, Continuous Univariate Distributions, Volume 1, Second Edition, New York: John Wiley \& Sons, 1994.

Judd, Kenneth L., "Projection Methods for Solving Aggregate Growth Models," Journal of Economic Theory, December 1992, 58, 410-452.

_ _ Numerical Methods in Economics, Cambridge, MA.: MIT Press, 1998. 
Kydland, Finn E. and Edward C. Prescott, "Time to Build and Aggregate Fluctuations," Econometrica, 1982, 50, 1345-1370.

_ and _ , "Hours and Employment Variation in Business Cycle Theory," Economic Theory, 1991, 1 (1), 63-81.

Lucas, Robert E., "Understanding Business Cycles," Carnegie Rochester Conference Series on Public Policy, 1977, 5, 7-29.

Malinvaud, Edmond, Profitability and Unemployment, Cambridge, England.: Cambridge Press, 1980.

Mork, Knut A., "Oil and the Macroeconomy when Prices go Up and Down," Journal of Political Economy, 1989, 79, 173-189.

Neftci, Salih N., "Are Economic Time Series Asymmetric over the Business Cycle?," Journal of Political Economy, 1984, 92, 307-28.

Phelps, Edmund S., "Substitution, Fixed Proportions, Growth and Distribution," International Economic Review, 1963, 4, 265-288.

Potter, Simon M., "A Nonlinear Approach to U.S. GNP," Journal of Applied Econometrics, 1995, 10, 109-125.

Rogerson, Richard, "Indivisible Labor, Lotteries and Equilibrium," Journal of Monetary Economics, 1988, 21, 3-16.

Rotemberg, Julio J. and Michael Woodford, "Real Business-Cycle Models and the Forecastable Movements in Output, Hours, and Consumption," American Economic Review, 1996, 86, 71-89.

Sheshinski, E., "Balanced Growth and Stability in the Johansen Vintage Model," Review of Economic Studies, 1967, 34, 239-248.

Sichel, Daniel E., "Business Cycle Asymmetry: A Deeper Look," Economic Inquiry, 1993, 31, 224-236.

Solow, R.M., "Substitution and Fixed Proportions in the Theory of Capital," Review of Economic Studies, 1962, 29, 207-218.

Tatom, John A., "Are the Macroeconomic Effects of Oil Changes Symmetric?," Carnegie Rochester Conference Series on Public Policy, 1988, 28, 325-368. 


\section{Appendix}

In this appendix we describe the derivation of the neoclassical vintage model, the solution methods for the dynamic model, details of the econometric procedure along with a complete description of the two-sector model used in section 5. At the end of this appendix we also provide complete tables for the moments of the neoclassical and putty-clay models with permanent technology shocks.

\section{Derivation of the Neoclassical Vintage Model:}

For the purpose of comparison, we construct a neoclassical model of vintage capital, initially introduced by Solow (1962). In this model, the restriction that ex post capital-labor ratios are fixed is removed. The two models are otherwise identical. Let $I_{t-j}$ denote aggregate investment in period $t-j$, and define the following capital aggregator

$$
K_{t}=\sum_{j=1}^{M} \theta_{t-j}^{1 / \alpha}\left(1-\delta_{j}\right) I_{t-j}
$$

Period t labor and output of machine $i$ created in period $t-j$ satisfies:

$$
L_{t, t-j}(i)=\left((1-\alpha) \theta_{i t-j} / W_{t}\right)^{1 / \alpha}\left(1-\delta_{j}\right) I_{t-j}
$$

and

$$
Y_{t, t-j}(i)=\theta_{i, t-j}^{1 / \alpha}\left((1-\alpha) / W_{t}\right)^{(1-\alpha) / \alpha}\left(1-\delta_{j}\right) I_{t-j}
$$

where $\left(1-\delta_{j}\right) I_{t-j}$ represents the capital remaining at time $t$ that was put in place at time $t-j$. Integrating over machines with respect to the distribution of $\theta_{i, t-j}$, and using the result that

$$
E\left(\theta_{i, t-j}^{1 / \alpha}\right)=\theta_{t-j}^{1 / \alpha} \exp \left(\frac{\sigma^{2}}{2 \alpha} \frac{1-\alpha}{\alpha}\right)
$$

provides the relationship between total vintage $t-j$ output and labor inputs:

$$
(1-\alpha) Y_{t, t-j}=W_{t} L_{t, t-j}
$$

where

$$
Y_{t, t-j}=A^{1-\alpha}\left(\theta_{t-j}^{1 / \alpha}\left(1-\delta_{j}\right) I_{t-j}\right)^{\alpha} L_{t, t-j}^{1-\alpha}
$$

and $A=\exp \left(\frac{\sigma^{2}}{2 \alpha}\right)$. Summing across vintages we obtain

$$
Y_{t}=\left((1-\alpha) A / W_{t}\right)^{(1-\alpha) / \alpha} K_{t}
$$




$$
L_{t}=\left((1-\alpha) A / W_{t}\right)^{1 / \alpha} K_{t} .
$$

Combining these two expressions gives the aggregate production function

$$
Y_{t}=A^{1-\alpha} K_{t}^{\alpha} L_{t}^{1-\alpha}
$$

where $L_{t}$ is aggregate labor input and $A=\exp \left(\frac{\sigma^{2}}{2 \alpha}\right)$ is a scale correction that results from aggregating across machines at the idiosyncratic level.

If we assume that $\delta_{j}=1-(1-\delta)^{j-1}$ and $M=\infty$, we obtain the following capital accumulation equation

$$
K_{t}=(1-\delta) K_{t-1}+\theta_{t-1}^{1 / \alpha} I_{t-1}
$$

Thus, shocks to embodied technological change are identical to shocks to the true economic cost of new capital goods.

\section{Solution Methods:}

The model consists of $2 M+N$ state variables, including average machine efficiencies, $X_{t-j}, j=1, \ldots, M$, and the quantity of new machines per vintage, $Q_{t-j}, j=$ $1, \ldots, M$, for each of the $M$ vintages in existence, and $N$ shocks. Owing to the log-normal distribution of $X_{i t}$, these state variables completely summarize the existing distribution of machines depicted in Figure 1. By choosing $M$ sufficiently large we provide an arbitrarily good approximation to the case $M=\infty$. For values of $M$ large enough to analyze business-cycle frequency properties of the model, the state-space is too large for the type of nonlinear state-space methods discussed in Judd (1998). Instead, depending on the purpose, we apply one of two methods that yield approximate solutions at relatively low computational cost.

The first method uses a log-linearization around the deterministic steady state of the equations describing the equilibrium. The resulting linear model, which includes $M$ leads and lags of $\ln (X)$ and $\ln (Q)$, is then solved using the AIM implementation of the Blanchard-Kahn method due to Anderson and Moore (1985). This algorithm yields accurate solutions for values at relatively low computational cost for $M$ up to 40, which is sufficiently large for an annual version of the model. For the quarterly version of the model, $M=40$ implies capital goods completely depreciate within 10 years, which seems to be an unrealistically short lifespan. Thus, following Gilchrist and Williams (1998a), we use polynomial distributed leads and lags to approximate the $M=\infty$ leads and lags of variables. For example, for some variable $u$ and 
coefficient sequence $\left\{a_{j}\right\}_{1}^{\infty}$, we approximate the sum $\sum_{j=1}^{\infty} a_{j} u_{t-j}$ by the polynomial distributed lag (or lead) $\frac{u_{t-1}}{B(L)}$, where $B(L)=b_{0}-b_{1} L-b_{2} L^{2}-\ldots-b_{p} L^{p}$ and $p$ is finite. For the putty-clay model we use $p=1$ and chose values corresponding to $b_{0}$ and $b_{1}$ that minimize the weighted squared deviations between the PDL representation and the original lag or lead structure; this approximations yields virtually no loss in accuracy for model simulations. This adds 8 equations to our model and reduces the maximum lead and lag from $M$ to 1 , thus drastically reducing the size of the companion form of the model. The solution time for this approximate model is trivial.

The log-linearized model, approximated in the manner described above, is used for the simulations reported in the paper except for those illustrating the asymmetrical response to large shocks shown in figure 6, which requires a method that preserves the nonlinearities of the model. For those simulations an extended path algorithm based on Fair and Taylor (1983) is used for a model with $M=160$. This method requires far more memory and CPU time than the linearization method described above. For small shocks, the two methods yield nearly identical answers.

Both of these methods compute "certainty-equivalent" solutions; that is, expectations are computed assuming all future shocks equal their mean values of zero. To address this issue, we used projection methods to solve a version of the model with small $M$. This approach, described in Judd (1992), uses polynomial approximations to the decision rules and multi-point quadrature to approximate expectation integrals and therefore does not impose certainty equivalence on the solutions. We found that the solutions were very close to those generated using the extended path algorithm, implying that the certainty equivalent solution provides a good approximation even in the presence of substantial non-linearities and reasonably large aggregate shocks.

\section{Econometric Methodology for Moment Matching Exercise}

In this section of the paper we present our moment matching methodology. We start by specifying a stochastic process for the log of output, hours and investment in the data which depends on an unknown parameter vector $\theta$ which is to be estimated. Our approach follows Rotemberg and Woodford's method of specifying a tightly parameterized low-order VAR system to characterize the data. Our data consists of private non-farm output, total private hours and non-residential business fixed 
investment (equipment and structures) for the period 1960-1997. Relative to GDP, the output and hours series exclude government and farm output as well as the imputed output obtained from owner-occupied housing. The output and hours series are thus defined in a mutually consistent manner. With the exception of agricultural investment in structures and machinery, the investment series is also consistent with the output and hours series. Both the output and the investment series are deflated using 1997 chain weighted-deflators.

After first removing a linear time trend from the hours series, we assume that the first difference of the log of output, the log of the investment/output ratio and the log of hours, $\left[\Delta y_{t}, i_{t}-y_{t}, h_{t}\right]$ can be represented using a two-lag stationary VAR representation. Defining

$$
\begin{aligned}
& u_{t}^{\prime}=\left[\Delta y_{t}, i_{t}-y_{t}, h_{t}, \Delta y_{t-1}, i_{t-1}-y_{t-1}, h_{t-1}\right], E\left(u_{t} u_{t}^{\prime}\right)=\Sigma_{u} \\
& e_{t}^{\prime}=\left[e_{t}^{y}, e_{t}^{i}, e_{t}^{h}\right], E\left(e_{t} e_{t}^{\prime}\right)=\Sigma_{e}, E\left(e_{t} e_{t+s}^{\prime}\right)=0 \text { for } s \neq 0
\end{aligned}
$$

we express the stochastic process for $u_{t}$ in companion form as:

$$
u_{t}=A u_{t-1}+v_{t}, A=\left[\begin{array}{c}
\Pi \\
I
\end{array}\right], v_{t}=\left[\begin{array}{c}
e_{t} \\
0
\end{array}\right], E\left(v_{t} v_{t}^{\prime}\right)=\Sigma_{v}
$$

where $\Pi$ is a matrix of VAR coefficients. Defining $D_{n}$ as the duplication matrix such that $D_{n} \operatorname{vech}\left(\Sigma_{e}\right)=\operatorname{vec}\left(\Sigma_{e}\right)$, the parameter vector $\xi$ and its associated variance is then:

$$
\xi=\left[\begin{array}{c}
\operatorname{vec}(\Pi) \\
\operatorname{vech}\left(\Sigma_{e}\right)
\end{array}\right], V_{\xi}=\left[\begin{array}{cc}
\Sigma_{e} \otimes \Sigma_{u}^{-1} & 0 \\
0 & \Sigma_{22}
\end{array}\right]
$$

where $\Sigma_{22}=2 D_{n}^{+}\left(\Sigma_{e} \otimes \Sigma_{e}\right)\left(D_{n}^{+}\right)^{\prime}$ for $D_{n}^{+}=\left(D_{n}^{\prime} D_{n}\right)^{-1} D_{n}^{\prime}$. (Hamilton (1994) pp 301-302 provides details.)

Given this specification for the stochastic process for output, hours and investment, we are interested in computing second moments of both the kth differences of these variables as well as second moments of the forecastable components of the kth differences, where the forecast is made conditional on time $t-k$ information. To obtain expressions for these second moments as functions of the underlying VAR parameters, we first express the kth differences in $y_{t+k}, i_{t+k}$ and $h_{t+k}$ as functions of data known at time $t$ and shocks that occur between $t$ and $t+k$. For $x=y, i, h$ we have:

$$
\Delta x_{t, k} \equiv x_{t+k}-x_{t}=b_{k}^{x} u_{t}+\sum_{j=1}^{k} d_{j}^{x} v_{t+j}
$$


where

$$
\begin{aligned}
& b_{k}^{y}=e_{1}^{\prime} \sum_{i=1}^{k} A^{i}, b_{k}^{i}=b_{k}^{y}+e_{2}^{\prime}\left(A^{k}-I\right), b_{k}^{h}=e_{3}^{\prime}\left(A^{k}-I\right) \\
& d_{j}^{y}=e_{1}^{\prime} \sum_{s=1}^{j} A^{s-1}, d_{j}^{i}=d_{j}^{y}+e_{2}^{\prime} A^{j-1}, d_{j}^{h}=e_{3}^{\prime} A^{j-1}
\end{aligned}
$$

Taking expectations as of time $\mathrm{t}$, the predictable components of the kth difference of $x$ is:

$$
\Delta \hat{x}_{t, k} \equiv E_{t}\left\{x_{t+k}-x_{t}\right\}=b_{k}^{x} u_{t}
$$

Computing second moments, we obtain an expressions for the variance of $\Delta x_{t, k}$

$$
\sigma_{x, k}^{2} \equiv E\left(\Delta x_{t, k}\right)^{2}=\left(b_{k}^{x}\right) \Sigma_{u}\left(b_{k}^{x}\right)^{\prime}+\sum_{j=1}^{k}\left(d_{j}^{x}\right) \Sigma_{v}\left(d_{j}^{x}\right)^{\prime}
$$

The covariance between $\Delta x_{t, k}$, and $\Delta y_{t, k}$ is obtained from

$$
\sigma_{x y, k} \equiv E\left(\Delta x_{t, k} \Delta y_{t, k}\right)=\left(b_{k}^{x}\right) \Sigma_{u}\left(b_{k}^{y}\right)^{\prime}+\sum_{j=1}^{k}\left(d_{j}^{x}\right) \Sigma_{v}\left(d_{j}^{y}\right)^{\prime} .
$$

Similarly, the variance of the predictable component of the kth difference in $x$ is simply

$$
\sigma_{\hat{x}, k}^{2} \equiv E\left(\Delta \hat{x}_{t, k}\right)^{2}=\left(b_{k}^{x}\right) \Sigma_{u}\left(b_{k}^{x}\right)^{\prime}
$$

while the covariance between the predictable components of the kth differences of $x$ with $y$ is obtained from:

$$
\sigma_{\hat{x y}, k} \equiv E\left(\Delta \hat{x}_{t, k} \Delta \hat{y}_{t, k}\right)=\left(b_{k}^{x}\right) \Sigma_{u}\left(b_{k}^{y}\right)^{\prime}
$$

To compute autocorrelations among kth differences, note that $E\left(\Delta x_{t+k, k} \Delta x_{t, k}\right)=$ $E\left(\Delta x_{t, 2 k} \Delta x_{t, k}\right)-E\left(\Delta x_{t, k}\right)^{2}$. From the expressions obtained above we then have $E\left(\Delta x_{t, 2 k} \Delta x_{t, k}\right)-E\left(\Delta x_{t, k}\right)^{2}=b_{2 k}^{x} \Sigma_{u}\left(b_{k}^{x}\right)^{\prime}-b_{k}^{x} \Sigma_{u}\left(b_{k}^{x}\right)^{\prime}$ implying that

$$
\rho_{x, k} \equiv \frac{E\left(\Delta x_{t+k, k}, \Delta x_{t, k}\right)}{E\left(\Delta x_{t, k}\right)^{2}}=\frac{\left(b_{2 k}^{x}-b_{k}^{x}\right) \Sigma_{u}\left(b_{k}^{x}\right)^{\prime}}{\left(b_{k}^{x}\right) \Sigma_{u}\left(b_{k}^{x}\right)^{\prime}}
$$

Using these expressions, we define two sets of moments. The first set of moments are the unconditional standard deviations of $\Delta i_{t, k}, \Delta h_{t, k}$ relative to the unconditional standard deviation of $\Delta y_{t, k}$, the unconditional correlations of $\Delta i_{t, k}, \Delta h_{t, k}$ with $\Delta y_{t, k}$, and the autocorrelations of $\Delta y_{t, k}, \Delta i_{t, k}$ and $\Delta h_{t, k}$ :

$$
h_{1, k}=\left[\frac{\sigma_{i, k}}{\sigma_{y, k}}, \frac{\sigma_{h, k}}{\sigma_{y, k}}, \frac{\sigma_{i y, k}}{\left(\sigma_{i, k} \sigma_{y, k}\right)}, \frac{\sigma_{h y, k}}{\left(\sigma_{h, k} \sigma_{y, k}\right)}, \rho_{y, k}, \rho_{i, k}, \rho_{h, k}\right]^{\prime} .
$$


For $k=1$ these moments are the unconditional moments considered in section 6 .

The second set of moments computes regression coefficients and correlations between the predictable components of $\Delta i_{t, k}, \Delta h_{t, k}$ and the predictable component of $\Delta y_{t, k}$. According to Rotemberg and Woodford, these measures of the underlying dynamic response of the system when away from steady state. Intuitively, these statistics capture the strength and magnitude of the expected comovements among output, investment and hours. By varying $k$, we vary the horizon over which the comovements between forecastable components are computed. The second set of moments also includes the ratio of the variance of the predictable component of $\Delta y_{t, k}$ relative to the total variance of $\Delta y_{t, k}$. Again, Rotemberg and Woodford view this statistic as providing a good indicator of the degree to which the model contains a propagation mechanism. Thus the second set of moments may be written as:

$$
g_{2, k}=\left[\frac{\sigma_{\hat{i}, k}}{\sigma_{\hat{y}, k}^{2}}, \frac{\sigma_{\hat{h y}, k}}{\sigma_{\hat{y}, k}^{2}}, \frac{\sigma_{\hat{i y, k}}}{\sigma_{\hat{\imath}, k} \sigma_{\hat{y}, k}}, \frac{\sigma_{\hat{h y}, k}}{\sigma_{\hat{h}, k} \sigma_{\hat{y}, k}}, \frac{\sigma_{\hat{y}, k}}{\sigma_{y, k}}\right]^{\prime} .
$$

where the first two elements are regression coefficients, the second two elements are correlations, and the final element is the variance ratio. Recognizing that both $g_{1,1}$ and $g_{2, k}$ are functions of $A, \Sigma_{u}, \Sigma_{v}$ and hence ultimately functions of the VAR parameter vector $\xi$, we obtain our moment vector of interest: $g(\xi)=\left[g_{1,1}^{\prime} g_{2, k}^{\prime}\right]^{\prime}$. To obtain an estimate of the variance of this moment vector, we use a Taylor series expansion of $g$ (the delta method) to obtain $V_{g}=\frac{\partial g}{\partial \xi^{\prime}} V_{\xi} \frac{\partial g}{\partial \xi}$.

We estimate the model parameters $\psi=\left[a, \rho_{A}, \rho_{\theta}, \rho_{L}, \frac{\sigma_{\theta}}{\sigma_{\theta}+\sigma_{A}}, \frac{\sigma_{L}}{\sigma_{\theta}+\sigma_{A}+\sigma_{L}}\right]$ by minimizing the distance between $g(\xi)$ and $g_{M}(\psi)$ where $g_{M}$ is the model's analog of $g(\xi)$. To obtain $g_{M}$ as a function of $\psi$ we rely on the fact that our model solution is linear and may be expressed in the first order companion form:

$$
X_{t}=A X_{t-1}+B U_{t}
$$

where $E\left(U_{t} U_{t}^{\prime}\right)=I$ and $X_{t}$ is a vector of model variables with $y_{t}=e_{y}^{\prime} X_{t}, c_{t}=e_{y}^{\prime} X_{t}$ and $h_{t}=e_{h}^{\prime} X_{t}$. The moment vector $g_{M}$ may then be computed as a function of $A, B$. Because the matrices $A, B$ are (nonlinear) functions of the underlying model parameters $\psi$, the moment vector $g_{M}$ is also a function of $\psi$. Standard errors for $\psi$ may then be obtained from $V_{\psi}=\left\{\frac{\partial g_{M}}{\partial \psi^{\prime}} V_{g}^{-1} \frac{\partial g_{M}}{\partial \psi}\right\}^{-1}$.

\section{Two Sector Model:}

In this section we provide a full description of the system of equations that characterize the equilibrium of the two-sector model. We set the final-goods price as 
the numeraire and define $P_{1, t}$ and $P_{2, t}$ as the relative output prices for each sector. Disembodied technology, $A_{t}$, affects both sectors equally. ${ }^{25}$ We define $\eta_{t}$ as the labor market shock.

Sectoral Production:

$$
\begin{gathered}
Y_{1, t}=\sum_{j=1}^{M}\left(1-\Phi\left(z_{t}^{t-j}-\sigma\right)\right)\left(1-\delta_{j}\right) Q_{t-j} X_{t-j} \\
L_{1, t}=\sum_{j=1}^{M}\left(1-\Phi\left(z_{t}^{t-j}\right)\right)\left(1-\delta_{j}\right) Q_{t-j} \\
Y_{2, t}=K_{t}^{\alpha} L_{2, t}^{1-\alpha} \\
K_{t}=(1-\delta) K_{t-1}+\theta_{t-1}^{1 / \alpha} I_{t-1} .
\end{gathered}
$$

Optimality conditions for sectoral labor and capital accumulation:

$$
\begin{gathered}
k_{t}=\alpha E_{t}\left\{\sum_{j=1}^{M} \tilde{R}_{t, t+j}\left(1-\delta_{j}\right)\left(1-\Phi\left(z_{t+j}^{t}-\sigma\right)\right) P_{1, t+j} X_{t}\right\} \\
k_{t}=E_{t}\left\{\sum_{j=1}^{M} \tilde{R}_{t, t+j}\left(1-\delta_{j}\right)\left(1-\Phi\left(z_{t+j}^{t}-\sigma\right)\right) P_{1, t+j} X_{t}\right. \\
\left.-\sum_{j=1}^{M} \tilde{R}_{t, t+j}\left(1-\delta_{j}\right)\left(1-\Phi\left(z_{t+j}^{t}\right)\right) W_{t+j}\right\} \\
\theta_{t}^{-1 / \alpha}=E_{t} R_{t, t+1}\left(\frac{\alpha P_{2, t+1} Y_{2, t+1}}{K_{t+1}}+(1-\delta) \theta_{t+1}^{-1 / \alpha}\right) \\
\frac{(1-\alpha) P_{2, t} Y_{2, t}}{L_{2, t}}=W_{t} \\
\frac{\phi\left(z_{t}^{t-j}-\sigma\right) P_{1, t} X_{t-j}}{\phi\left(z_{t}^{t-j}\right)}=W_{t}, \quad j=1, \ldots M .
\end{gathered}
$$

This last expression equates marginal products across all vintages. It could have alternatively been written as $z_{t}^{t-j} \equiv \frac{1}{\sigma}\left(\log W_{t}-\log P_{1, t} X_{t-j}+\frac{1}{2} \sigma^{2}\right)$.

Household first order conditions:

$$
U_{c, t}=\frac{\beta}{1+n} E_{t} R_{t, t+1} U_{c, t+1}
$$

\footnotetext{
${ }^{25}$ Note that the effect of the level of disembodied technology on the first-order conditions of firms is captured by the output price terms.
} 


$$
U_{c, t} \eta_{t} W_{t}+U_{L, t}=0
$$

Aggregate output and resource constraints:

$$
\begin{gathered}
Y_{t}=A_{t} Y_{1, t}^{\lambda} Y_{2, t}^{1-\lambda} \\
C_{t}=Y_{t}-k_{t} Q_{t}-I_{t} \\
L_{t}=L_{1, t}+L_{2, t} .
\end{gathered}
$$

Shocks:

$$
\begin{aligned}
\ln \left(A_{t}\right) & =\rho_{A} \ln \left(A_{t-1}\right)+e_{A, t}, \text { with } E\left(e_{A, t}^{2}\right)=\sigma_{A}^{2} \\
\ln \left(\theta_{t}\right) & =\rho_{\theta} \ln \left(\theta_{t-1}\right)+e_{\theta, t}, \quad \text { with } E\left(e_{\theta, t}^{2}\right)=\sigma_{\theta}^{2} \\
\ln \left(\eta_{t}\right) & =\rho_{L} \ln \left(\eta_{t-1}\right)+e_{\eta, t}, \quad \text { with } E\left(e_{\eta, t}^{2}\right)=\sigma_{L}^{2}
\end{aligned}
$$

\section{Permanent Technology Shocks:}

Tables 6 and 7 report the unconditional and forecastable moments, respectively, resulting from permanent technology shocks for the two models as well as the statistics estimated in the data. 
Table 6: Unconditional Moments - Permanent Technology Shocks

\begin{tabular}{l|rr|rr|rr}
\hline \hline & \multicolumn{2}{|c|}{ Neoclassical Model } & \multicolumn{2}{|c|}{ Putty-Clay Model } & \multicolumn{2}{|c}{ Data } \\
& Disemb. & Embod. & Disemb. & Embod. & Est. & S. E. \\
\hline & & & & & & \\
$\sigma_{\Delta c} / \sigma_{\Delta y}$ & 0.55 & 1.13 & 0.70 & 2.87 & 0.36 & 0.02 \\
$\sigma_{\Delta h} / \sigma_{\Delta y}$ & 0.36 & 1.57 & 0.09 & 0.91 & 0.66 & 0.04 \\
$\sigma_{\Delta i} / \sigma_{\Delta y}$ & 2.15 & 6.03 & 1.76 & 8.14 & 1.82 & 0.11 \\
$\sigma_{\Delta p} / \sigma_{\Delta y}$ & 0.65 & 0.69 & 0.91 & 0.77 & 0.68 & 0.04 \\
& & & & & & \\
$\operatorname{cor}\left(\Delta c_{t}, \Delta y_{t}\right)$ & 0.99 & -0.83 & 0.99 & -0.12 & 0.52 & 0.06 \\
$\operatorname{cor}\left(\Delta h_{t}, \Delta y_{t}\right)$ & 0.98 & 0.95 & 0.96 & 0.68 & 0.74 & 0.04 \\
$\operatorname{cor}\left(\Delta i_{t}, \Delta y_{t}\right)$ & 0.99 & 0.97 & 0.99 & 0.53 & 0.60 & 0.05 \\
$\operatorname{cor}\left(\Delta p_{t}, \Delta y_{t}\right)$ & 0.99 & -0.71 & 1.00 & 0.50 & 0.76 & 0.03 \\
& & & & & & \\
$\operatorname{cor}\left(\Delta y_{t}, \Delta y_{t-1}\right)$ & 0.01 & 0.07 & 0.04 & 0.80 & 0.31 & 0.08 \\
$\operatorname{cor}\left(\Delta c_{t}, \Delta c_{t-1}\right)$ & 0.10 & 0.05 & 0.10 & 0.06 & 0.34 & 0.08 \\
$\operatorname{cor}\left(\Delta h_{t}, \Delta h_{t-1}\right)$ & -0.03 & -0.03 & 0.20 & 0.20 & 0.60 & 0.06 \\
$\operatorname{cor}\left(\Delta i_{t}, \Delta i_{t-1}\right)$ & -0.02 & -0.02 & -0.01 & -0.02 & 0.50 & 0.07 \\
$\operatorname{cor}\left(\Delta p_{t}, \Delta p_{t-1}\right)$ & 0.06 & 0.18 & 0.03 & 0.73 & 0.60 & 0.06 \\
& & & & & & \\
\hline \hline
\end{tabular}

Table 7: Forecastable Moments - Permanent Technology Shocks

\begin{tabular}{l|rr|rr|rr}
\hline \hline & \multicolumn{2}{|c|}{ Neoclassical Model } & \multicolumn{2}{|c|}{ Putty-Clay Model } & \multicolumn{2}{|c}{ Data } \\
& Disemb. & Embod. & Disemb. & Embod. & Est. & S. E. \\
\hline & & & & & & \\
$\operatorname{cor}\left(\Delta \hat{c}_{t, 4}, \Delta \hat{y}_{t, 4}\right)$ & 1.00 & 1.00 & 1.00 & 1.00 & 0.95 & 0.07 \\
$\operatorname{cor}\left(\Delta \hat{h}_{t, 4}, \Delta \hat{y}_{t, 4}\right)$ & -1.00 & -1.00 & 0.44 & 0.44 & 0.86 & 0.06 \\
$\operatorname{cor}\left(\Delta \hat{i}_{t, 4}, \Delta \hat{y}_{t, 4}\right)$ & -1.00 & -1.00 & -0.98 & -0.98 & 0.76 & 0.07 \\
$\operatorname{cor}\left(\Delta \hat{p}_{t, 4}, \Delta \hat{y}_{t, 4}\right)$ & 1.00 & 1.00 & 0.95 & 0.95 & 0.76 & 0.10 \\
& & & & & & \\
$\alpha_{\left(\Delta \hat{c}_{t, 4}, \Delta \hat{y}_{t, 4}\right)}$ & 3.18 & 3.18 & 1.61 & 1.61 & 0.22 & 0.07 \\
$\alpha_{\left(\Delta \hat{h}_{t, 4}, \Delta \hat{y}_{t, 4}\right)}$ & -1.68 & -1.68 & 0.14 & 0.14 & 0.59 & 0.09 \\
$\alpha_{\left(\Delta \hat{i}_{t, 4}, \Delta \hat{y}_{t, 4}\right)}$ & -4.44 & -4.44 & -0.49 & -0.49 & 1.70 & 0.24 \\
$\alpha_{\left(\Delta \hat{p}_{t, 4}, \Delta \hat{y}_{t, 4}\right)}$ & 2.68 & 2.68 & 0.86 & 0.86 & 0.41 & 0.09 \\
$\sigma_{\Delta \hat{y}_{t, 4}} / \sigma_{\Delta y_{t, 4}}$ & & & & & & \\
$\sigma_{\Delta \hat{y}_{t, 8}} / \sigma_{\Delta y_{t, 8}}$ & 0.06 & 0.25 & 0.14 & 0.83 & 0.64 & 0.06 \\
$\sigma_{\Delta \hat{y}_{t, 16}} / \sigma_{\Delta y_{t, 16}}$ & 0.08 & 0.30 & 0.17 & 0.77 & 0.71 & 0.07 \\
\multicolumn{2}{|c|}{0.09} & 0.31 & 0.18 & 0.67 & 0.65 & 0.06 \\
\hline \hline
\end{tabular}

